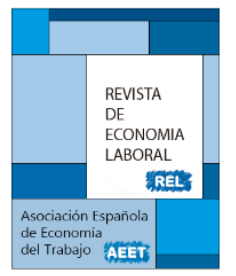

\title{
LA CRISIS ECONÓMICA, LAS REFORMAS LABORALES Y LA NEGOCIACIÓN COLECTIVA
}

\author{
José Ignacio Pérez Infante \\ Economista
}

Recibido Septiembre 2016; Aceptado Noviembre 2016

\section{Resumen}

El objetivo principal del artículo es analizar si la crisis económica y las reformas laborales aprobadas a lo largo de la crisis han tenido alguna incidencia sobre la capacidad negociadora de los distintos interlocutores sociales. Para ello, se explica cómo las consecuencias de la crisis, no contrarrestadas por la recuperación económica que se produce desde mediados de 2013, han podido influir en la capacidad de los trabajadores y los sindicatos para negociar las condiciones de trabajo y salariales, dificultándolas, aparte de que la recuperación económica ha ido acompañada de una mayor precarización del empleo, lo que parece que va en la misma dirección de debilitar la posición de los trabajadores. Por otro lado, las reformas laborales aprobadas en los últimos años, como las que se producen en materia de despido y de modificación de las condiciones de trabajo $y$, sobre todo, en la regulación de la negociación colectiva, refuerzan las razones que van en el mismo sentido que la crisis económica de empeorar la posición de los trabajadores. Y ese debilitamiento de la negociación colectiva de los trabajadores tiene como consecuencia más relevante la devaluación salarial.

Palabras clave: Crisis, Reforma laboral, Debilitamiento de la capacidad negociadora de los trabajadores, Devaluación salarial, Desigualdad.

Clasificación JEL: J51, J52, J53.

\section{Abstract}

The main objective of the article is to analyse whether the economic crisis and the labour reforms approved during the crisis have had an impact on the bargaining power of the different social partners. This is explained by how the consequences of the crisis, not offset by the economic recovery since mid-2013, have been able to influence the capacity of workers and trade unions to negotiate working and wage conditions, hindering them; apart from the fact that the economic recovery has been accompanied by a greater precariousness of employment, which seems to be in the same direction of weakening the position of the workers. On the other hand, the labour reforms approved in recent years, such as those concerning dismissals and changes in working conditions and, above all, in the regulation of collective bargaining, reinforce the effects of the economic crisis in the direction of worsening the position of workers. And the most relevant consequence of the weakening of workers' collective bargaining is wage devaluation.

Key words: Crisis, Labour reform, Weakening of workers' bargaining power, Wage devaluation, Inequality.

JEL Classification: J51, J52, J53.

C Revista de Economía Laboral 


\section{Introducción: la negociación colectiva y la determinación salarial}

La economía convencional analiza la determinación de los salarios como la de los precios de una mercancía cualquiera por el juego de la oferta y la demanda de trabajo. De hecho, en el modelo neoclásico ideal, el de competencia perfecta, el salario de equilibrio será aquél para el que la demanda de trabajo por parte de los empresarios se iguale con la oferta de trabajo por parte de las personas potencialmente activas. Esta situación de equilibrio será en la que la economía tenderá a encontrarse normalmente en condiciones de competencia perfecta y de plena flexibilidad al alza y a la baja de los salarios. En esas condiciones en la situación de equilibrio existirá pleno empleo, el paro involuntario será nulo y solo podrá existir paro bien porque sea voluntario, porque las personas potencialmente activas solo deseen trabajar a un salario superior al de equilibrio, bien porque no se cumplan las condiciones de competencia perfecta y los salarios no sean flexibles porque existan determinadas regulaciones, imperfecciones o rigideces del mercado de trabajo. Eso es lo que puede ocurrir cuando no exista una perfecta información de las condiciones de trabajo y salariales por parte de empresarios y/o trabajadores o, lo que es más relevante para el análisis, cuando determinados grupos de trabajadores o el conjunto de ellos no actúen aisladamente sino que se agrupen y puedan influir en la cuantía salarial correspondiente.

La situación no es muy diferente si, en vez del modelo neoclásico, se tiene en cuenta el modelo neokeynesiano, aunque en este caso pueda existir paro (tasa de paro positiva), pese a que los salarios sean de equilibrio, considerándose a ese paro natural, estructural o de equilibrio. A esa tasa de paro natural se la conoce también como NAIRU, tasa no aceleradora de inflación, por sus siglas en inglés. Y esa tasa de paro natural $\left(\mathrm{u}^{*}\right)$, no cíclica o coyuntural ${ }^{1}$, sería una función creciente de los salarios reales (W/P), y de un conjunto de fenómenos, de carácter institucional, que impiden la libre competencia y la flexibilidad total de los salarios, agrupados en la variable $\mathrm{z}^{2}$.

$$
\begin{gathered}
\mathrm{u}^{*}=\mathrm{f}(\mathrm{W} / \mathrm{P}, \mathrm{z}) \\
++
\end{gathered}
$$

\footnotetext{
${ }^{1}$ El paro en media anual, sería la suma del paro cíclico o coyuntural y del paro natural o de equilibrio. El paro estacional solo tendría sentido para los periodos inferiores al año.

${ }^{2}$ Véase, entre otros, Blanchard et al. (2012).
} 
Y, además, los salarios reales dependerán de forma decreciente del paro total y efectivo (u), no solo del de equilibrio, y de forma creciente de esos fenómenos considerados en la variable $\mathrm{z}$, de carácter institucional ${ }^{3}$, que se consideran normalmente como "imperfecciones" o como elementos perturbadores del mercado de trabajo y que explican la existencia de paro, incluso en equilibrio, y que se califica por estos economistas como natural, ya que no desaparecerá sino se suprime o aminora la influencia de esos factores.

$$
\mathrm{W} / \mathrm{P}=\mathrm{g}(\mathrm{u}, \mathrm{z})
$$

$\mathrm{Y}$ entre esas "imperfecciones" o "elementos perturbadores" se encontrarán, según la generalidad de los economistas defensores de este tipo de explicación, el poder o la fuerza de los sindicatos en la determinación de los salarios, la existencia de negociación colectiva, relacionada, normalmente, con la propia presencia de los sindicatos, que impediría el libre juego de la oferta y la demanda de trabajo, o la regulación laboral, es decir, la misma existencia del derecho del trabajo, en materias como el despido y la contratación o las condiciones de trabajo, que puede limitar la plena adaptación de la plantilla de las empresas o de esas condiciones de trabajo, entre las que se encuentran la cuantía salarial, al cambio de la situación económica o con la finalidad de conseguir mayores beneficios. Asimismo, entre esos elementos perturbadores del mercado de trabajo podrían encontrarse, según muchos economistas convencionales, la generosidad del sistema de protección al desempleo, ya que podría obstaculizar la búsqueda activa de empleo por parte de las personas sin trabajo y aumentar, en consecuencia, la duración del tiempo que se encuentran en paro.

Y si esto fuera así, la única forma de reducir e, incluso, de eliminar ese paro que excede al cíclico o coyuntural, y que se califica de natural, sería mediante reformas laborales que hiciesen al mercado de trabajo más competitivo (más cercano al de competencia perfecta) y a los salarios más flexibles, reformas que debieran ir en la dirección de reducir la regulación del mercado de trabajo, abaratar y facilitar el despido, eliminar o, al menos, amortiguar las limitaciones a la contratación y las diferencias relacionadas con los costes laborales entre la contratación indefinida y la temporal, facilitar la modificación de las condiciones de trabajo, disminuir el grado de protección de las

\footnotetext{
3 Aunque pueden incluirse factores que afectan a la rigidez de los mercados de productos y a la determinación de los precios, como la falta de competencia de esos mercados, normalmente la economía convencional hace hincapié en los factores relacionados con las rigideces e imperfecciones del mercado de trabajo.
} 
prestaciones por desempleo, reducir la fuerza sindical y debilitar el papel en la negociación colectiva de los trabajadores o de sus representantes.

Pero, a pesar de las numerosísimas reformas laborales aprobadas desde el Estatuto de los Trabajadores de 19804, la tasa de paro en España apenas ha bajado desde 1979 del 8\%5 y esas reformas, según los economistas convencionales y la mayoría de los organismos económicos nacionales y extranjeros (salvo la OIT), no habrían sido suficientes, recomendándose continuamente nuevas reformas laborales, nuevas desregulaciones del mercado de trabajo y nuevas medidas flexibilizadoras, cuyas consecuencias más patentes, como se explicará en el artículo, serán, más que el aumento del empleo y la reducción del paro, la pérdida de capacidad negociadora de los trabajadores y el aumento de la pobreza y la desigualdad, así como la desprotección de los trabajadores.

Y ello por varias razones. En primer lugar, porque la evolución del empleo no depende exclusiva ni principalmente de las condiciones del mercado de trabajo sino de otras variables mucho más amplias y complejas, entre las que figuran las relacionadas con el modelo de producción y de crecimiento económico. En segundo lugar, porque la existencia de condiciones cíclicas o coyunturales desfavorables que pueden explicar niveles de paro muy elevados pueden ser muy duraderas y difíciles de corregir sobre todo en economías como la española muy dependientes y con poca capacidad de instrumentación de políticas económicas autónomas. En tercer lugar, porque, como consecuencia de todo ello, las reformas laborales pueden tener una escasa capacidad de incidir en el empleo y el paro, aparte de que los efectos de las reformas sobre esas variables sean lentos y paulatinos en el tiempo. Y, en cuarto lugar, porque la flexibilidad salarial a la baja puede provocar, en vez de un aumento de la producción y el empleo, como suele plantearse por la economía convencional, la situación contraria, un retroceso de la producción y el empleo porque esa reducción salarial puede influir negativamente en los ingresos de los trabajadores y, por lo tanto, en la demanda efectiva de los mismos, contrarrestando el posible efecto positivo que la disminución de los salarios pueda tener en el coste laboral de los empresarios.

Y el problema es que la economía convencional tiene una serie de problemas que pueden cuestionar, limitar y condicionar su análisis y, desde luego, sus conclusiones y recomendaciones. Y en este sentido,

${ }^{4}$ Véase a este respecto Pérez Infante (1999, 2009, 2010a, 2010b, 2015a, 2015b, 2015c).

${ }^{5}$ El 7,9\% en el segundo trimestre de 2007. 
podrían destacarse seis aspectos del análisis convencional. Primero, que contemplar el salario como cualquier otro precio y, en concreto, la mercancía que se compra y se vende en el mercado de trabajo como el de cualquiera otra, significa prescindir y abstraerse de la naturaleza de relación social que supone esa compra-venta entre empresarios y trabajadores, diferente a una mera relación entre cosas, mercancíadinero, y, por lo tanto, de cualquier consideración del mercado de trabajo como una institución social.

Segundo, que la mercancía que se intercambia en el mercado de trabajo no es el trabajo sin más, y desde luego no el trabajo realizado como ocurre en el caso de las restantes mercancías, sino la fuerza de trabajo o capacidad de trabajar, lo que significa que el empresario compra a cambio de un salario la posibilidad de utilizar (con las limitaciones que establezcan las normas legales o los convenios colectivos) esa capacidad de trabajar en el proceso productivo apropiándose de sus resultados.

Tercero, que al ser la demanda de trabajo una demanda derivada de la actividad económica y, por lo tanto, de la producción y el empleo, no parece que sea muy realista considerar en el análisis del mercado de trabajo, como muchas veces se hace, a esta variable de forma marginal e incluirla dentro del ceteris paribus, como si fuera una variable dada y constante, contemplando al salario como la variable principal o, incluso, única en la determinación del empleo.

Cuarto, que los elementos que suponen perturbaciones o imperfecciones al mercado de trabajo, y que, por consiguiente, se consideran como fenómenos o variables exógenas (vienen dadas desde fuera) al mercado de trabajo y, en consecuencia, al análisis de dicho mercado, en realidad son en su mayoría aspectos indisolubles, esenciales y característicos de las sociedades actuales, como la existencia de los sindicatos y de la negociación colectiva, por lo que parece discutible y problemático considerarlos como fenómenos perturbadores que en el mejor de los casos habrá que reducirlos o limitarlos.

Quinto, y en el mismo sentido, en relación con el punto central de artículo, la negociación colectiva es la forma más normal y habitual de la determinación de los salarios en las sociedades capitalistas actuales y no el mero juego de la oferta y la demanda como si de una bolsa de valores se tratara, ya que, como luego se comprobará, para en torno al 80\% de los trabajadores la forma principal de establecer el salario es la negociación colectiva, aparte de que el contenido principal de esta negociación sigue siendo el salario, que de hecho se recoge en España en prácticamente la totalidad de los convenios colectivos. 
Y, sexto, la economía convencional se fija prioritariamente en una de las dos dimensiones del salario, el salario como coste laboral de las empresas, haciendo una consideración marginal en el mejor de los casos, si no es prescindiendo totalmente, de la otra dimensión del salario, el salario como ingreso de los trabajadores asalariados, que significan en un país como España más del 80\% de las personas ocupadas, y, por ende, como uno de los determinantes principales de la demanda de consumo, que representa casi las dos terceras partes del total de la demanda agregada de la economía española. Y, como se ha señalado, esta cuestión es muy relevante, pues puede ocurrir que la disminución del salario, en lugar de incentivar la producción y el empleo, como ocurriría si el único efecto de esa disminución fuera la reducción del coste laboral, llegara a tener el efecto contrario al previsto generalmente por la economía convencional, retrocediendo la producción y el empleo.

Pues bien, el análisis del mercado de trabajo, mejor dicho de la relación social de intercambio de la fuerza de trabajo, y, en particular, de la determinación de los salarios, no debiera realizarse, como plantea la economía convencional, tanto la neoclásica como la neokeynesiana, haciendo abstracción de los sindicatos y de la negociación colectiva y, en general, de las relaciones sociales, fundamentándose en un modelo ideal basado en unas condiciones e hipótesis difíciles de encajar y compatibilizar con la realidad de las sociedades actuales, puesto que esa determinación de los salarios depende de factores no estrictamente económicos, como las relaciones de poder entre empresarios y trabajadores, es decir, entre las distintas clases sociales, como ya desde la década de los sesenta del siglo pasado defendía el economista italiano Sraffa (1960).

Con este planteamiento diferente al de la economía convencional es como se va a abordar el contenido del artículo, en concreto, las consecuencias sobre la negociación colectiva y la capacidad de negociación de los trabajadores de la crisis económica y las reformas laborales aprobadas en los últimos años. Así en el segundo apartado del artículo se analiza sintéticamente y de forma general la influencia en la capacidad negociadora de los trabajadores de esos dos fenómenos. En el tercer apartado se tiene en cuenta los posibles efectos de la crisis y las reformas laborales en la cobertura de la negociación colectiva, o, lo que es lo mismo, en la evolución del número de los trabajadores afectados por los convenios colectivos. En el cuarto se consideran las posibles consecuencias de la crisis y las reformas laborales sobre la estructura de los convenios colectivos y su ámbito funcional y territorial, y se hará hincapié por su importancia en la capacidad negociadora de los 
trabajadores en la cuestión del grado de centralización de esos convenios. En el quinto apartado se reflexiona sobre los efectos económicos y sociales del debilitamiento de la capacidad negociadora de los trabajadores, en concreto la devaluación salarial y el aumento de la desigualdad. Y, por último, en el sexto apartado se destacan las conclusiones principales del artículo.

\section{Crisis económica, reformas laborales y capacidad de negociación de los trabajadores}

Ya se ha dicho que la relación esencial de lo que se llama por la economía convencional el mercado de trabajo (el término de mercado ya tiene unas claras connotaciones ideológicas sobre el enfoque del análisis que efectúa ese tipo de economía) no es una relación entre cosas, entre mercancías, sino una relación social, más, en concreto, una relación de poder, en particular entre empresarios y trabajadores, o, lo que es lo mismo, entre la capacidad negociadora de esas dos clases sociales, y esa relación por su propia naturaleza no es inmutable ni constante en el tiempo, sino que puede variar por una serie de factores entre los que vamos a considerar en este artículo dos muy relevantes en los últimos años, la crisis económica y las respuestas de los distintos gobiernos a esa crisis desde la primavera de 2010: la política de austeridad y, sobre todo, las reformas laborales.

Comencemos con la crisis económica que tiene lugar en España a partir de finales de 2007 y de forma más clara y rotunda desde la primavera de 2008. En otras ocasiones ya se han expuesto las causas y características de la Gran Recesión en España ${ }^{6}$, ahora nos limitamos a las consecuencias sobre las relaciones de poder entre empresarios y trabajadores y más específicamente sobre la capacidad negociadora de los trabajadores. Es evidente que entre los efectos más negativos que ha tenido la crisis económica en España, más intensamente, además, que en otros países de nuestro entorno político y económico, destacan los que se producen sobre el empleo y el paro.

La destrucción del empleo que se produce en España desde el inicio de la crisis tiene una magnitud desconocida en otras situaciones negativas anteriores (como las crisis del período 1976-1984 y la de 1991-1993) y mucho más negativa que la que se produce en los últimos años de crisis económica en el resto de los países de la Unión Europea,

\footnotetext{
6 Véase Pérez Infante (2015b). Y en una línea de análisis similar puede consultarse
} Ruesga (2016) y García (2014). 
salvo la excepción de Grecia. Y esta destrucción de empleo es especialmente aguda en los dos primeros años de la crisis: en 2008, al disminuir la población ocupada a lo largo del año en casi setecientas mil personas (-662.000), y en 2009, al retroceder el empleo en cerca de un millón doscientas mil personas (-1.164.900).

Ahora bien, la política de incentivos económicos, de carácter keynesiana, puesta en marcha en la primavera de 2009, coherente con las recomendaciones de aplicar medidas fiscales para estimular de forma rápida la demanda interna de los países acordadas en la reunión del G-20 de noviembre de 2008, pero solo vigente durante un año, frenó la intensidad del descenso del empleo en 2010, hasta algo más de doscientos mil empleos menos (-215.500). Pero, como consecuencia del final de esa política económica anticíclica y su sustitución por otra política procíclica (que acentúa la desfavorable situación económica) de austeridad, en respuesta a los acuerdos alcanzados por los jefes de gobierno de la Unión Europea en mayo de 2010, el retroceso del empleo vuelve a agravarse en 2011 hasta superar el medio millón de ocupados (-521.999) y, sobre todo, en 2012, año en el que el descenso a lo largo del año excede al de 2008 y se acerca al de 2009, con más de ochocientos mil personas empleadas menos (-813.600). En 2013, y pese al final de la recesión y el inicio de la recuperación económica desde mediados del año, el empleo sigue disminuyendo (-204.200), aunque menos acentuadamente, para finalmente aumentar en $2014(+433.000)$ y en $2015(+525.100)$.

Pero, aun así, el aumento del empleo desde la primavera de 2013 ha sido hasta ahora totalmente insuficiente para compensar la fortísima destrucción del empleo que se había producido desde el comienzo de la crisis económica en España, en concreto en las dos recesiones que se detectan en la economía española desde inicios de 2008 (descenso intertrimestral del PIB real desestacionalizado desde el tercer trimestre de 2008 hasta el cuarto de 2009 y desde el primero de 2011 hasta el segundo de 2013), por lo que, si se considera el descenso total del empleo que se produce desde el momento en que comienza a disminuir (cuarto trimestre de 2007) hasta el último dato disponible (segundo trimestre de 2016), ese descenso asciende todavía a casi dos millones y medio de personas (-2.452.400), lo que supone que en términos relativos al final del período considerado el empleo es casi un $12 \%$ menos del que existía antes de desencadenarse la crisis económica en España.

$\mathrm{Y}$ este fortísimo descenso del empleo explica el enorme crecimiento del paro que se produce en nuestro país desde el comienzo de la crisis económica y que, según las estimaciones de la Encuesta de 
Población Activa (EPA), alcanza el punto álgido en el primer trimestre de 2013, cuando todavía sigue la economía española en recesión, trimestre en el que el número de personas desempleadas alcanza el máximo histórico de casi seis millones trescientas mil personas (6.278.300), lo que significa que se había multiplicado por más de tres veces desde el mínimo del paro que se había logrado en la anterior fase de expansión económica en el segundo trimestre de 2007. Por su parte, la tasa de paro, que antes del inicio de la crisis económica se situaba por debajo del 8\% (el 7,9\% en el segundo trimestre de 2007), el nivel más bajo que se había alcanzado desde 1979, se multiplica por 3,5 veces, hasta situarse también en el primer trimestre de 2013 en el máximo histórico de prácticamente el 27\% (26,9\%).

Aunque tanto el nivel como la tasa de paro descienden desde el comienzo de la recuperación económica, el retroceso, como ocurría en el caso de la evolución del empleo, es claramente insuficiente para contrarrestar las consecuencias negativas en el paro de la crisis económica, al multiplicarse desde mediados de 2007 hasta el segundo trimestre de 2016 las dos magnitudes por más de 2,5 y ascender en ese trimestre de 2016 el nivel de paro a más de cuatro millones y medio de personas, lo que significa un aumento total cercano a tres millones de personas, y alcanzar la tasa de paro en ese trimestre el $20 \%$, la quinta parte de la población activa.

Pero, aparte de la gravedad del problema del paro en España por el número de personas en esa situación y por lo elevado del porcentaje que representa sobre la población activa, esa gravedad se acentúa aún más si se tiene en cuenta su duración. Así, el paro de larga duración (personas que llevan buscando empleo, al menos, un año) afecta en el segundo trimestre de 2016 a más de dos millones seiscientas mil personas, casi el $60 \%$ del paro total, cuando a principios de 2008 apenas representaba el $20 \%$. Y, lo que es peor, se constata la gran relevancia del paro de muy larga duración (personas que llevan buscando empleo, al menos, dos años), que concierne a dos millones de personas, más del $40 \%(42,8 \%)$ del paro total.

Pues parece evidente que la influencia de la crisis en la evolución y situación actual del empleo y el paro deber tener alguna repercusión en la relación entre empresarios y trabajadores a la hora de negociar las condiciones de trabajo y determinar el salario, al debilitar la capacidad negociadora de los trabajadores $y$, por el contrario, reforzar el poder de los empresarios para imponer condiciones más favorables a sus intereses en detrimento de los de los trabajadores. Y ese debilitamiento de la capacidad negociadora de los trabajadores puede no haberse alterado sensiblemente durante la 
recuperación económica, no solo por su insuficiencia para la restauración de los niveles de empleo y de paro anteriores a los de la crisis sino también por la creciente precarización del empleo que se está creando $^{7}$, que hace aun más difícil la negociación de las condiciones de trabajo por parte de los asalariados. En efecto, aunque de la crisis económica se derivó una disminución de la tasa de temporalidad (porcentaje de asalariados con contratos temporales), no por la mejora de la calidad del empleo subsiguiente sino porque la crisis afectó con una fuerza especial al sector de la construcción con tasas de temporalidad muy superiores a la media, desde el comienzo de la recuperación dicha tasa ha aumentado en casi tres puntos porcentuales, hasta situarse en el segundo trimestre de 2016 en el $25,7 \%$, debido a que más del $60 \%$ del crecimiento del empleo asalariado que se ha producido desde entonces corresponde al empleo temporal.

$\mathrm{Y}$ en ese debilitamiento de la capacidad negociadora también influye el avance de la parcialidad que se produce ya desde el inicio de la crisis, debido a la estrategia de algunas empresas de convertir empleos a tiempo completo en empleos a tiempo parcial con el objetivo de mantener, al menos en parte, el empleo, pero, sobre todo, desde la aprobación de la reforma laboral de 2012, por la flexibilización que se produce en la modalidad contractual de tiempo parcial, primero, por la posibilidad de realizar horas extraordinarias y, después, por la facilidad para realizar las calificadas como horas complementarias 8 . De hecho, la tasa de parcialidad (porcentaje de empleo a tiempo parcial respecto del total), que no llegaba al $12 \%$ antes de la crisis crece hasta superar el $16 \%(16,4 \%)$ en el segundo trimestre de 2014 y estabilizarse después en valores cercanos a ese porcentaje $(15,3 \%$ en el segundo trimestre de 2016) ${ }^{9}$. Este avance de la tasa de parcialidad se explica porque desde el

\footnotetext{
7 En relación con este proceso véase Pérez Infante (2015b, 2016a, 2016b), Cebrián (2016) y Gómez (2016).

${ }^{8}$ El Real Decreto-ley 3/2012 y la Ley 3/2012 que regularon la reforma laboral de 2012 permitieron la realización de las horas extraordinarias en los contratos a tiempo parcial, posibilidad que se había suprimido en 1998, lo que supuso una notable flexibilización de la jornada laboral en este tipo de contratación. Posteriormente, el Real Decreto-ley 16/2013, de 20 de diciembre, volvió a suprimir la posibilidad de realizar horas extraordinarias, pero facilitó considerablemente las horas complementarias creadas en 1998, como, por ejemplo, permitiendo su realización en los contratos a tiempo parcial temporales cuando hasta ese momento estaban limitadas a los contratos a tiempo parcial indefinidos.

9 Posiblemente, este freno al crecimiento de la tasa de parcialidad que se produce desde mediados de 2014 puede deberse al cambio de regulación de la contratación a tiempo parcial por la supresión de la posibilidad de realización de las horas extraordinarias, aunque se faciliten las horas complementarias, y también por el inicio de la
} 
comienzo de la crisis, mientras que el empleo a tiempo completo se redujo en prácticamente tres millones de personas, el empleo a tiempo parcial aumentó en el mismo período en más de medio millón de personas.

Pero el debilitamiento de la capacidad negociadora no solo puede ser consecuencia de la repercusión muy negativa de la crisis en el empleo y el paro y de la insuficiencia y las características de la recuperación económica, sino que también puede estar influida por la estrategia de la política económica y laboral seguida por los distintos gobiernos a partir de la primavera de 2010, eso sí siguiendo las presiones de las instituciones y distintos gobiernos de la Unión Europea y de algún otro organismo internacional (FMI, OCDE) y nacional (el Banco de España) ${ }^{10}$. Los dos componentes de esa política económica y laboral son, por un lado, la austeridad fiscal y, por otro lado, las reformas laborales.

La política de austeridad fiscal, por su propio carácter procíclico (al reducir el gasto público y aumentar los impuestos), como se señala, por ejemplo, en Pérez Infante (2015d), ha agravado la situación y las consecuencias de la Gran Recesión, lo que ha debilitado aún más la capacidad negociadora de los trabajadores, aparte de que esta también se ha podido ver afectada por los efectos, tanto directos en el sector público como indirectos en otros sectores, de la política de austeridad fiscal en el retroceso del empleo y de los salarios de los trabajadores de las Administraciones Públicas.

Pero la estrategia deliberada de los gobiernos para desequilibrar el marco de las relaciones laborales en detrimento de los trabajadores, así como de sus representantes, en particular los sindicatos, se ha reflejado principalmente en las reformas laborales aprobadas a partir de la primavera de 2010, en concreto las de 2010, 2011, 2012 y las posteriores a ese año11. Aunque, en general, casi todas las reformas laborales aprobadas con posterioridad al Estatuto de los Trabajadores de 1980 han tenido como objetivo fundamental la flexibilidad y desregulación del mercado de trabajo y del marco de las relaciones

recuperación económica un año antes que puede propiciar que los empresarios vuelvan a transformar contratos a tiempo parcial en contratos a tiempo completo.

10 El Banco de España parece que ha estado siempre más preocupado por los problemas laborales, reclamando, continuamente, la aprobación de duras reformas laborales, que por los propios del sistema financiero, sin duda alguna más responsable de la Gran Recesión en España y de la situación económica actual que los posibles problemas de funcionamiento del mercado de trabajo.

11 Para un análisis de las reformas laborales aprobadas a lo largo de la crisis económica puede verse Pérez Infante (2013a, 2015b, 2015c, 2015d). 
laborales, ese objetivo de la flexibilidad es muy evidente en las de 2010, 2011 y, sobre todo, en la de 2012, sin duda la más radical y desequilibradora de todas las reformas laborales aprobadas a lo largo de los últimos treinta y cinco años ${ }^{12}$. Este objetivo de la flexibilidad laboral en concordancia con el planteamiento y las recomendaciones ya señaladas de la economía convencional y de la mayoría de los organismos económicos ha ido dirigido principalmente a la mayor facilidad para adaptar el tamaño de las plantillas (flexibilidad externa), tanto a través de mecanismos de entrada en el empleo (contratación) como de salida del empleo (despido), para modificar las condiciones de trabajo de las empresas (flexibilidad interna), o para facilitar el ajuste de los salarios reales y hasta de los monetarios (flexibilidad salarial) a la situación económica, pero, sobre todo, para mejorar la rentabilidad de las empresas a través de diversos instrumentos, entre los que sobresale la reforma de la negociación colectiva.

Ya se ha dicho que, entre estas reformas laborales, destaca la de 2012, por su amplitud, intensidad y consecuencias. Dentro de los numerosos cambios que introduce esa reforma ${ }^{13}$, y en relación con la incidencia de la misma sobre la capacidad negociadora de los trabajadores ${ }^{14}$, se pueden destacar la mayor facilidad y el abaratamiento del despido, con un numeroso y variado conjunto de medidas que afectan tanto al despido procedente como al improcedente $\mathrm{y}$ al individual como al colectivo ${ }^{15}$, y las mayores posibilidades de modificar las condiciones de trabajo de las empresas, sobre todo en relación con la suspensión temporal del contrato, la reducción de la jornada laboral, la flexibilidad funcional y geográfica dentro de la empresa, e, incluso, la cuantía salarial, que en el caso de que esas condiciones de trabajo y salariales no estén acordadas en convenio colectivo estatutario o que mejoren las de ese convenio pueden

12 El análisis de la reforma laboral de 2012 y las reformas posteriores que la complementan e incluso acentúan sus rasgos flexibilizadores se realiza en Valdés DalRé (2016).

13 Un análisis detallado de la reforma laboral de 2012 se realiza en Casas, RodríguezPiñeiro y Valdés Dal-Ré (2013) y Guamán e Illueca (2012). También puede consultarse Casas (2014) y Pérez Infante (2015b, 2015c, 2015d).

14 Véase Pérez Infante (2015b).

15 Como la reducción de la indemnización por despido improcedente de 45 a 33 días de salario por año de servicio, con la rebaja correspondiente de los topes de 42 a 24 mensualidades, la supresión de los salarios de tramitación, la eliminación de la autorización administrativa de los despidos colectivos y las mayores posibilidades del despido objetivo procedente por la notable flexibilización de sus causas, principalmente las económicas para lo que será suficiente con tres trimestres consecutivos de reducción interanual de las ventas o los ingresos ordinarios. 
realizarse por decisión unilateral del empresario sin necesidad alguna de consenso o acuerdo con los trabajadores y sus representantes ${ }^{16}$.

Y, además, la reforma laboral de 2012, que introdujo importantes modificaciones en la negociación colectiva, afectó a los mecanismos de determinación salarial (flexibilidad salarial), lo que puede incidir en la capacidad negociadora de los trabajadores. En este sentido, caben señalar tres importantes modificaciones de la negociación colectiva ${ }^{17}$.

La primera, la prioridad aplicativa de los convenios de empresa en distintas materias de las relaciones laborales, entre las que se incluyen las relativas a la jornada laboral y la cuantía salarial, lo que significa que pueden modificar, tanto para mejorar o empeorar, un convenio de ámbito superior, como es el caso de los convenios sectoriales provinciales, autonómicos y nacionales.

Esta prioridad aplicativa es, además, absoluta, no cabe ninguna posibilidad de que se pacte lo contrario en un convenio de ámbito superior $o$ en un acuerdo interprofesional de ámbito nacional o autonómico, como sí se permitía, en cambio, con la reforma laboral de 2011, aprobada por el gobierno socialista por el Real Decreto-ley 7/2011, de 11 de junio ${ }^{18}$.

La prioridad aplicativa de los convenios de empresa, aparte de romper definitivamente con los principios establecidos inicialmente en la redacción del Estatuto de los Trabajadores de 1980 de no concurrencia de varios convenios en una misma empresa y, en cualquier caso, de la jerarquía de los convenios, de mayor a menor ámbito ${ }^{19}$, supone la posibilidad de que una empresa, que puede ser de

16 Aparte de la posibilidad de modificar las condiciones de trabajo por decisión unilateral del empresario, algo que es una ruptura radical con la situación anterior, se facilitan considerablemente las causas que permiten esa modificación al hacerlas muy generales y amplias, bastando con que estén relacionadas con la competitividad, productividad u organización técnica o del trabajo de la empresa, sin precisar que sea necesario, como ocurría en la legislación anterior, que las modificaciones contribuyan a evitar una evolución futura negativa de la empresa o a mejorar la situación y perspectivas de las mismas.

17 Véase el artículo de Cruz Villalón (2016) y el de Pérez Infante (2016a).

18 Para un análisis de las reformas laborales en materia de negociación colectiva de 2011 y 2012 puede verse Pérez Infante (2013a, 2013b).

19 Las reformas laborales de 1994 y de 2011 ya habían afectado, aunque menos agudamente que la de 2012, al principio de no concurrencia y también al de la jerarquía de los convenios, la primera por la posibilidad de que los convenios provinciales y autonómicos modificaran convenios de ámbito superior y la segunda porque estableció la prioridad aplicativa de los convenios de empresas, aunque condicionada a que no se pactase lo contrario en un convenio o acuerdo interprofesional autonómico o nacional. 
reducido tamaño, con una relación de dependencia grande entre los trabajadores y empresarios y en la que el grado de sindicación sea muy escaso o nulo, pueda imponer las condiciones de trabajo, incluida la salarial, sobre las pactadas para el sector en el área geográfica correspondiente, lo que, sin duda, se convierte en un importante mecanismo de debilitamiento de la negociación colectiva.

La segunda modificación es el fin de la ultraactividad, que suponía la vigencia indefinida del convenio, aunque hubiese terminado la prevista en el mismo, hasta que se suscribiera uno nuevo, siempre que hubiera transcurrido un año desde la denuncia del convenio por alguna de las partes, y, por consiguiente, desde que se hubiera cumplido el plazo inicialmente previsto de vigencia.

Aunque, en el caso de existir un convenio de ámbito superior ese sería el aplicable, lo normal en los convenios vigentes en el momento de la aprobación de la reforma de 2012 era que las condiciones de trabajo de esos convenios de ámbito superior fuesen inferiores o peores que las del convenio que perdía la ultraactividad, pues entonces un convenio de empresa solo podía mejorar los de ámbito superior y no empeorarlas. Pero, además, si no existiera un convenio de ámbito superior, al final de la ultraactividad la empresa se quedaría sin convenio de aplicación. Tanto en una como en otra situación (aplicación de convenio superior o inexistencia de convenio de aplicación) las condiciones de trabajo de los trabajadores habrían empeorado y la negociación de un nuevo convenio se produciría desde una situación más débil y con menor capacidad de negociación de los trabajadores, sobre todo mientras se mantuvieran las desfavorables y negativas consecuencias de la crisis económica ${ }^{20}$, máxime con la posibilidad existente después de la reforma laboral de que, al no existir convenio, la empresa modifique las condiciones de trabajo y salariales unilateralmente.

El tercer cambio es la mayor facilidad para las modificaciones de las condiciones de trabajo y los descuelgues salariales (aplicación de un salario inferior al acordado en convenio colectivo) por varias razones, como la mayor flexibilidad y permeabilidad de las causas relacionadas con las dificultades económicas de las empresas que posibilitan la inaplicación del convenio colectivo (bastando con una reducción interanual de los ingresos ordinarios o ventas de las empresas durante dos trimestres consecutivos) o la facultad, si no se alcanzara acuerdo

\footnotetext{
20 Aunque una Sentencia del Tribunal Supremo de 22 de diciembre de 2014 entiende que el contenido derogado por la pérdida de la ultraactividad puede seguir siendo exigible porque las condiciones de trabajo pactadas se habrían incorporado al contrato individual de trabajo.
} 
entre la empresa y los trabajadores para la inaplicación del convenio colectivo, de que cualquiera de las partes puede someter a la Comisión Consultiva Nacional de Convenios Colectivos o a las correspondientes comisiones autonómicas, según el caso, el arbitraje obligatorio de las discrepancias.

Teniendo en cuenta la participación de las administraciones públicas en esas comisiones, y aparte de que difícilmente puede entenderse la interpretación del Tribunal Constitucional de que esa participación no afecta a la autonomía de las partes, esa posibilidad de arbitraje obligatorio puede llegar a debilitar aún más la situación de los trabajadores ante la propuesta de inaplicación del convenio por parte de la empresa.

\section{El impacto de la gran recesión y las reformas laborales en la evolución de los convenios y su cobertura}

Veamos ahora cómo la Gran Recesión con sus consecuencias sobre el empleo y el paro y las reformas laborales aprobadas desde 2010, sobre todo la de 2012, han podido incidir en el número de convenios colectivos y en su cobertura de empresas y de trabajadores.

Para ello se plantean dos problemas previos muy relevantes. El primero, la dificultad de separar los efectos de la crisis económica de los de las reformas laborales. $\mathrm{Y}$, el segundo, las insuficiencias $\mathrm{y}$ deficiencias de la Estadística de Convenios Colectivos, elaborada con base en las Hojas Estadísticas que deben cumplimentar las comisiones negociadoras de los convenios y que deben registrarse ante la autoridad laboral correspondiente con el mismo convenio, que limitan y condicionan el análisis sobre el número de convenios vigentes y el número de empresas y de trabajadores cubiertos por los mismos ${ }^{21}$.

De estos problemas y deficiencias destacan dos, la falta de información precisa y completa del número de empresas y de trabajadores cubiertos por los convenios colectivos sectoriales (los que afectan a más de una empresa) y la elevada provisionalidad de los datos de los últimos años, lo que significa que los últimos que pueden

21 Varios trabajos del autor estudian estas limitaciones y dificultades. En concreto, puede consultarse Pérez Infante (2014, 2015a, 2017). 
considerarse definitivos hasta que no se llegue a mediados de 2017 son los de $2014^{22}$.

Considerando las cifras correspondientes al período 2007-2015 (cuadro 1), el número de convenios vigentes con efectos económicos en cada año, que había alcanzado el máximo histórico en 2007 (6.016), disminuye desde ese año hasta 2012 (4.376) con una pérdida de casi mil seiscientos cincuenta convenios en cinco años, volviendo a aumentar a partir de ese año y situándose en 4.589 convenios en 2013 y en 5.185 en 2014 , cifra esta última que ya supera a la de 2010 (5.067). En 2015, con cifras todavía provisionales (no se convertirán en definitivas hasta los datos correspondientes al 31 de mayo de 2017) el número de convenios correspondiente a los registrados hasta el 31 de julio de 2016 se sitúa en 5.090, cifra que, aunque inferior a la definitiva de 2014, es superior, incluso a las definitivas desde 2010 hasta 2013. Es fácil constatar en las cifras anteriores una evolución de carácter procíclico: disminuyen durante el período de Gran Recesión y aumentan durante el período de recuperación económica.

En cuanto al número de empresas y de trabajadores cubiertos por los convenios vigentes con efectos económicos en cada año el carácter procíclico de la evolución, incluso, se acentúa. Así, el número de empresas cubiertas por convenios colectivos, que había alcanzado el valor máximo en 2008, con algo más de un millón seiscientos mil, disminuye, igualmente, hasta 2012, año en el que ese número se sitúa en menos de un millón doscientos mil (1.162.000) y a partir de 2013 comienza a aumentar hasta superar la cifra de un millón cuatrocientos mil (1.436.900) en 2014, cifra que ya es cercana a la de 2010. Algo similar ocurre con el número de trabajadores, que disminuye desde 2009 (el máximo se había alcanzado, asimismo, en 2008 con casi doce millones de trabajadores cubiertos por convenios colectivos) hasta, también, 2012, con prácticamente un millón menos de trabajadores cubiertos que en el máximo de 2008. En 2013 y 2014 aumenta el número de trabajadores cubiertos por convenios colectivos, hasta situarse en el último año con los datos ya definitivos en 10.304.700, cifra que, en este caso, solo supera a las de 2012 y 2013.

22 Con los convenios registrados hasta el 31 de mayo de 2016, es decir, transcurridos casi dos años y medio desde el último día de 2014. 
Cuadro 1: Evolución del número de convenios, empresas y trabajadores en el período 20052016.

\begin{tabular}{|c|c|c|c|c|c|c|c|c|c|c|c|c|}
\hline & 2005 & 2006 & 2007 & 2008 & 2009 & 2010 & 2011 & 2012 & 2013 & 2014 & $2015^{(1)}$ & $2016^{(1)}$ \\
\hline \multicolumn{13}{|c|}{ Número de convenios } \\
\hline TOTAL & 5.776 & 5.887 & 6.016 & 5.987 & 5.689 & 5.067 & 4.585 & 4.376 & 4.589 & 5.185 & 4.460 & 1.910 \\
\hline Conv.empresa & 4.353 & 4.459 & 4.598 & 4.539 & 4.323 & 3.802 & 3.422 & 3.234 & 3.395 & 4.004 & 3.650 & 1.474 \\
\hline Otros & 1.423 & 1.428 & 1.418 & 1.448 & 1.366 & 1.265 & 1.163 & 1.142 & 1.194 & 1.181 & 810 & 436 \\
\hline \multicolumn{13}{|c|}{ No Empresas (miles) } \\
\hline TOTAL & $1.314,0$ & $1.457,0$ & $1.413,7$ & $1.605,2$ & $1.520,5$ & $1.481,1$ & $1.170,9$ & $1.162,0$ & $1.312,9$ & $1.436,9$ & $1.069,8$ & 546,1 \\
\hline Conv.empresa & 4,4 & 4,5 & 4,6 & 4,5 & 4,3 & 3,8 & 3,4 & 3,2 & 3,4 & 4,0 & 3,7 & 1,5 \\
\hline Otros & $1.309,6$ & $1.452,5$ & $1.409,1$ & $1.600,7$ & $1.516,2$ & $1.477,3$ & $1.167,5$ & $1.158,7$ & $1.309,5$ & $1.432,9$ & $1.066,1$ & 544,6 \\
\hline \multicolumn{13}{|c|}{$\mathrm{N}^{\mathrm{o}}$ Trabajadores (miles) } \\
\hline TOTAL & $10.755,7$ & $11.119,3$ & $11.606,5$ & $11.968,1$ & $11.557,8$ & $10.794,3$ & $10.662,8$ & $10.099,0$ & $10.265,4$ & $10.304,7$ & $7.818,2$ & $4.813,7$ \\
\hline Conv.empresa & $1.159,7$ & $1.224,4$ & $1.261,1$ & $1.215,3$ & $1.114,6$ & 923,2 & 929,0 & 925,7 & 932,7 & 867,2 & 720,3 & 295,7 \\
\hline Otros & $9.596,0$ & $9.894,9$ & $10.345,4$ & $10.752,9$ & $10.443,2$ & $9.871,1$ & $9.733,8$ & $9.173,3$ & $9.332,7$ & $9.437,5$ & $7.097,9$ & $4.518,0$ \\
\hline \multicolumn{13}{|c|}{ Ratio Empresas por convenio } \\
\hline TOTAL & 227,5 & 247,5 & 235,0 & 268,1 & 267,3 & 292,3 & 255,4 & 265,5 & 286,1 & 277,1 & 239,9 & 285,9 \\
\hline Conv.empresa & 1,0 & 1,0 & 1,0 & 1,0 & 1,0 & 1,0 & 1,0 & 1,0 & 1,0 & 1,0 & 1,0 & 1,0 \\
\hline Otros & 920,3 & $1.017,2$ & 993,7 & $1.105,4$ & $1.110,0$ & $1.167,9$ & $1.003,9$ & $1.014,6$ & $1.096,7$ & $1.213,3$ & $1.316,2$ & $1.249,1$ \\
\hline \multicolumn{13}{|c|}{ Ratio Trabajadores por convenio } \\
\hline TOTAL & $1.862,1$ & $1.888,8$ & $1.929,3$ & $1.999,0$ & $2.031,6$ & $2.130,3$ & $2.325,6$ & $2.307,8$ & $2.237,0$ & $1.987,4$ & $1.753,0$ & $2.520,3$ \\
\hline Conv.empresa & 266,4 & 274,6 & 274,3 & 267,7 & 257,8 & 242,8 & 271,5 & 286,3 & 274,7 & 216,6 & 197,3 & 200,6 \\
\hline Otros & $6.743,5$ & $6.929,2$ & $7.295,8$ & $7.426,0$ & $7.645,1$ & $7.803,3$ & $8.369,6$ & $8.032,6$ & $7.816,3$ & $7.991,1$ & $8.762,9$ & $10.362,3$ \\
\hline \multicolumn{13}{|c|}{ Ratio Trabajadores por empresa } \\
\hline TOTAL & 8,2 & 7,6 & 8,2 & 7,5 & 7,6 & 7,3 & 9,1 & 8,7 & 7,8 & 7,2 & 7,3 & 8,8 \\
\hline Conv.empresa & 266,4 & 274,6 & 274,3 & 267,7 & 257,8 & 242,8 & 271,5 & 286,3 & 274,7 & 216,6 & 197,3 & 200,6 \\
\hline Otros & 7,3 & 6,8 & 7,3 & 6,7 & 6,9 & 6,7 & 8,3 & 7,9 & 7,1 & 6,6 & 6,7 & 8,3 \\
\hline
\end{tabular}

Fuente: MEYSS, Estadística de Convenios Colectivos de Trabajo.

Nota: (1) Datos provisionales. Convenios registrados hasta el 31 de mayo de 2016.

(C) Revista de Economía Laboral 
El descenso, que en el número de convenios ya se producía en 2008 por los efectos de la crisis económica, no se ve correspondido con las cifras de empresas y de trabajadores cubiertos por esos convenios en ese año, que sigue aumentando, debido a la importancia que tienen los convenios plurianuales, firmados en los años anteriores de expansión económica ${ }^{23}$, así como por el retraso que suele tener la negociación colectiva desde el momento en que se inicia hasta que se suscribe el correspondiente convenio.

Por lo tanto, el efecto de la crisis económica en el número de empresas y de trabajadores cubiertos por los convenios colectivos se constata con claridad desde 2010, pero a partir de 2013 por el proceso de recuperación de la economía española el proceso de reducción se frena y comienzan a aumentar tanto la cifra de convenios vigentes con efectos económicos como la de las empresas cubiertas y la de los trabajadores cubiertos por los convenios vigentes. Ahora bien, los datos de 2015, como todavía son provisionales, no siguen esta tendencia creciente iniciada en 2013. Si para corregir la incidencia de la provisionalidad en las cifra se consideran los datos de distintos años en una fecha equivalente, por ejemplo el 31 de diciembre de cada año, entonces la situación cambia sustancialmente (cuadro 2) y no solo el número de convenios sino también el de empresas y de trabajadores cubiertos aumenta en 2015, superando en el caso de los convenios las cifras de 2013 y 2014 y en el de las empresas y los trabajadores a las cifras de todos los años que transcurren desde 2010, inclusive, lo que parece que es significativo de que la tendencia creciente iniciada en 2013 se mantiene en 2015 y de que comienza a compensarse los efectos de la crisis en las cifras correspondientes.

Pero centrándonos en los trabajadores cubiertos, que sería el dato más relevante para analizar la incidencia e importancia de la negociación colectiva, ese número puede estar afectado tanto por la crisis económica, al reducirse la población ocupada y, por lo tanto, la que puede potencialmente estar cubierta por los convenios colectivos, como por las consecuencias de las reformas laborales si estas debilitaran la negociación colectiva y provocaran el reforzamiento del poder de los empresarios, que en muchos casos pueden preferir regular las relaciones laborales por los contratos individuales o por otro tipo de acuerdos diferentes a los de los convenios estatutarios.

23 Y cuyo número de empresas y de trabajadores, normalmente, no se corrige a lo largo de la vigencia del convenio, no teniendo en cuenta, por ejemplo, los efectos muy relevantes durante las crisis de la desaparición de empresas y de destrucción de empleo en esas cifras, como se explica en Pérez Infante (2016a, 2017).

(C) Revista de Economía Laboral 
Cuadro 2: Datos de los convenios con efectos económicos en el período 2007-2015 con las cifras de los convenios registrados hasta el 31 de diciembre de cada año.

\begin{tabular}{|c|c|c|c|c|c|c|c|c|c|}
\hline & 2007 & 2008 & 2009 & 2010 & 2011 & 2012 & 2013 & 2014 & 2015 \\
\hline \multicolumn{10}{|l|}{$\mathrm{N}^{\circ}$ convenios } \\
\hline Total & 4.230 & 4.073 & 4.082 & 2.704 & 2.532 & 2.611 & 1.691 & 1.728 & 2.268 \\
\hline Convenios de empresa & 3.247 & 3.027 & 3.098 & 1.937 & 1.872 & 1.979 & 1.181 & 1.255 & 1.667 \\
\hline Otros convenios & 983 & 1.046 & 984 & 767 & 660 & 632 & 510 & 473 & 601 \\
\hline \multicolumn{10}{|l|}{$\mathrm{N}^{\circ}$ empresas (miles) } \\
\hline Total & $1.058,9$ & $1.035,4$ & $1.106,6$ & 893,4 & 695,0 & 685,5 & 603,2 & 723,7 & 948,5 \\
\hline Convenios de empresa & 3,2 & 3,0 & 3,1 & 1,9 & 1,9 & 2,0 & 1,2 & 1,3 & 1,7 \\
\hline Otros convenios & $1.055,7$ & $1.032,4$ & $1.103,5$ & 891,5 & 693,1 & 683,5 & 602,0 & 722,5 & 946,8 \\
\hline \multicolumn{10}{|l|}{$\mathrm{N}^{\circ}$ trabajadores (miles) } \\
\hline Total & $8.412,1$ & $8.801,7$ & $8.675,7$ & $7.093,1$ & $6.267,4$ & $6.078,4$ & $5.040,5$ & $4.756,0$ & $6.484,8$ \\
\hline Convenios de empresa & 989,0 & 849,4 & 821,2 & 463,1 & 518,5 & 645,4 & 339,6 & 336,0 & 374,5 \\
\hline Otros convenios & $7.423,0$ & $7.952,4$ & $7.854,5$ & $6.629,9$ & $5.749,0$ & $5.433,0$ & $4.700,9$ & $4.420,0$ & $6.110,3$ \\
\hline
\end{tabular}

C Revista de Economía Laboral 
Si se pretende aislar esos dos efectos y excluir la influencia de la crisis en el empleo para considerar únicamente la repercusión de las reformas laborales, en vez utilizar la cifra absoluta de trabajadores cubiertos por convenios, habría que servirse de la llamada tasa de cobertura, que puede definirse como el porcentaje de trabajadores realmente cubiertos por la negociación colectiva en relación con los trabajadores potencialmente cubiertos por la misma, descontando, por consiguiente, a aquellos trabajadores excluidos legalmente de la negociación colectiva, como los funcionarios públicos, y otros colectivos de trabajadores apartados de hecho de la misma, como los empleados de hogar.

Para calcular la tasa de cobertura se utilizan para el denominador los datos de afiliaciones de asalariados a la seguridad social $^{24}$, excluidos los que pertenecen al sistema de empleados del hogar, los del régimen de autónomos y el resto de trabajadores por cuenta propia, como los del régimen especial del mar, y en el numerador los trabajadores cubiertos por la negociación colectiva obtenidos de la Estadística de Convenios Colectivos. Los valores así calculados de la tasa de cobertura, condicionados por la fiabilidad de las cifras de trabajadores con convenio colectivo, pueden estar algo infravalorados porque el denominador esté sobrevalorado, ya que se utilizan los datos de afiliaciones $y$ no de personas afiliadas (considerando más de una vez a los asalariados pluriafiliados por estar pluriocupados) y porque al no disponerse del número de personas afiliadas que son funcionarios públicos ${ }^{25}$ no han sido excluidos de la cifra de trabajadores potencialmente cubiertos por la negociación colectiva. Aun así, pensamos que estos problemas que atañen al cálculo de la tasa de cobertura pueden influir en la cuantía de esa tasa pero, no necesariamente, en su evolución, si aumenta o disminuye, que es el asunto principal que interesa en este análisis.

Pues bien, la tasa de cobertura ha tenido la siguiente evolución desde 2007: crece desde el $76,2 \%$ de ese año hasta el 80,3\% en 2009 , disminuye hasta el $75,8 \%$ en 2012 y vuelve a crecer en 2013 , hasta situarse en ese año en el 80,4\%, tasa ligeramente superior a la de 2009

\footnotetext{
${ }^{24}$ Se utilizan los datos de afiliaciones a la seguridad social y no los de la EPA, porque esta última considera como ocupados a los trabajadores irregulares (no afiliados) y que, normalmente, no están cubiertos por la negociación colectiva. Véase Pérez Infante (2017).

25 Considerados únicamente los pertenecientes al sistema de seguridad social y, por lo tanto, excluidos los funcionarios adscritos a los sistemas de mutualismo administrativo, MUFACE (funcionarios civiles del Estado), ISFAS (fuerzas armadas) y MUGEJU (funcionarios judiciales).
}

(C) Revista de Economía Laboral 
y más de cuatro puntos porcentuales por encima de la de 2007, lo que parece que contradice la opinión bastante generalizada, sobre todo entre los especialistas más críticos a la reforma laboral de 2012, sobre el retroceso de la tasa de cobertura de los últimos años ${ }^{26}$. En 2014 se produce un descenso inferior en un punto porcentual, pero la tasa de ese año $(79,5 \%)$ todavía supone un avance en relación con la de 2007 de más de tres puntos.

El aumento de 2007 a 2009 es debido a que en los dos primeros años desde el inicio de la crisis el número de trabajadores con convenio (numerador) no desciende con la misma intensidad que el de los afiliados (ocupados) asalariados (denominador) por el peso de los convenios plurianuales firmados con anterioridad a la crisis y porque en muchos de los casos el número de trabajadores de esos convenios plurianuales no se corrige posteriormente, considerándose la misma cifra de trabajadores cubiertos para todo el período de vigencia, independientemente de la evolución a lo largo de ese período del empleo en las empresas correspondientes. En cambio, a partir de 2010 y a medida que van ganando importancia relativa los nuevos convenios y perdiéndola los convenios firmados antes de la crisis, cada vez es más evidente el descenso del empleo en las cifras de trabajadores cubiertos.

Pero en 2013 se vuelve a producir un nuevo incremento de la tasa de cobertura que se puede explicar, aparte de por la posible incidencia del aumento del empleo que se deriva de la recuperación económica, porque algunos de los efectos de la reforma laboral pueden ser contradictorios entre sí, ya que el posible debilitamiento de la negociación colectiva puede ser desfavorable para la cobertura de trabajadores por la negociación colectiva, pero el final de la ultraactividad puede incentivar la firma de nuevos convenios para superar la situación de la pérdida de vigencia de muchos convenios. Y ese efecto no se nota principalmente en el año de la reforma laboral, 2012, sino al siguiente, 2013, debido a la disposición transitoria de la Ley 3/2012, que aprueba definitivamente esa reforma, que establece que el período de un año que debe transcurrir desde el final de la vigencia (más concretamente desde la denuncia del convenio por algunas de las partes) para que el convenio deje de estar en ultraactividad se computa, retrasándolo, a partir de la entrada en vigor de esa ley, es decir, el nueve de julio de 2013.

\footnotetext{
${ }^{26}$ El sentido de la evolución de la tasa de cobertura se mantiene si esa tasa se calcula con los datos de la EPA, en lugar de con las afiliaciones a la Seguridad Social, como se constata en Cruz Villalón (2016).
} 
Como consecuencia de ello, en la segunda mitad de 2013 se produce un importante avance en la firma de nuevos convenios para superar la situación de que muchos de ellos dejaron entonces (a partir de esa fecha) de estar ultraactivos y perdieron realmente su vigencia, independientemente de que la fecha de término del convenio se produjera anteriormente, lo que influye en el aumento de la tasa de cobertura (téngase en cuenta que los convenios ultraactivos no se consideraban en muchos casos como convenios vigentes, sobre todo hasta que no se desarrolló y perfeccionó el Registro de Convenios Colectivos creado en 2010), contrarrestando así los posibles efectos negativos de la reforma laboral en la tasa de cobertura.

La importancia creciente de la firma de nuevos convenios colectivos en 2013, sobre todo en la segunda mitad de ese año, es evidente con las cifras disponibles desde 2011. De hecho, los nuevos convenios (los firmados en el año) ascienden a casi dos mil quinientos en 2013 (2.432), cuando en 2011 (año anterior a la reforma laboral de 2012) apenas eran 1.700 y en 2012 eran un poco más de 2.00027. Este crecimiento en el número de convenios firmados en el año influye en el número de trabajadores cubiertos con nuevos convenios que no llegaba a tres millones y medio en 2009 y 2010 y que en 2013 se acercaba a los cinco millones y medio. Ello se refleja en el porcentaje sobre los convenios vigentes o con efectos económicos en el año, según la fecha de la firma del convenio: en 2009 los que se firmaron en los años anteriores suponían más de las dos terceras partes de los convenios vigentes, con lo que el porcentaje de los convenios firmados en el año en que se inicia los efectos económicos o en uno posterior no llegaba al $30 \%$, mientras que en 2013 los porcentajes ascendían a menos del 50\% en el primer caso y a más de $50 \%$ en el segundo (cuadro 3 ).

Ahora bien, el número de nuevos convenios firmados en 2013 influido por la importancia de convenios acumulados que han dejado de estar ultraactivos desde la entrada en vigor de los efectos del final de la ultraactividad de la reforma laboral de 2012 en julio de 2013, se frena en 2014 y vuelven a suponer bastante más del 50\% los convenios plurianuales, tanto en lo que respecta al número de convenios $(65,3 \%)$ como en lo que respecta al número de trabajadores cubiertos $(72,2 \%)$.

27 En realidad, consideramos como nuevos convenios a los firmados en el año o en un año posterior pero con efectos económicos en ese año. 
Cuadro 3: Convenios y trabajadores por año de efectos económicos, según fecha de firma del convenio (2005-2016).

\begin{tabular}{|c|c|c|c|c|c|c|c|c|c|c|c|c|}
\hline & 2005 & 2006 & 2007 & 2008 & 2009 & 2010 & 2011 & 2012 & 2013 & 2014 & $2015^{(1)}$ & $2016^{(1)}$ \\
\hline Número & & & - & - & - & - & - & - & - & - & - & - \\
\hline Convenios & & & - & - & - & - & - & - & - & - & _ & - \\
\hline Total & 5.776 & 5.887 & 6.016 & 5.987 & 5.689 & 5.067 & 4.585 & 4.376 & 4.589 & 5.185 & 4.460 & 1.910 \\
\hline Año firma anterior al de ef. econ. & $3.195,0$ & $3.418,0$ & 3.561 & 3.406 & 3.677 & 3.285 & 2.869 & 2.295 & 2.157 & 3.388 & 3.162 & 1.627 \\
\hline Año firma igual al de ef. econ. & $2.202,0$ & $2.055,0$ & 2.059 & 2.145 & 1.502 & 1.370 & 1.183 & 1.340 & 2.010 & 1.473 & 1.150 & 283 \\
\hline Año firma posterior al de ef. econ. & 379,0 & 414,0 & 396 & 436 & 510 & 412 & 533 & 741 & 422 & 324 & 148 & 0 \\
\hline Trabajadores (miles) & - & - & - & - & - & - & - & - & - & - & - & - \\
\hline Total & $10.755,7$ & $11.119,3$ & $11.606,5$ & $11.968,1$ & $11.557,8$ & $10.794,3$ & $10.662,8$ & $10.099,0$ & $10.265,4$ & $10.304,7$ & $7.818,2$ & $4.813,7$ \\
\hline Año firma anterior al de ef. econ. & $6.131,6$ & $7.004,6$ & $6.143,6$ & $7.258,3$ & $8.098,6$ & $7.406,0$ & $6.661,9$ & $4.229,4$ & $4.802,5$ & $7.436,7$ & $4.493,3$ & $4.435,7$ \\
\hline Año firma igual al de ef. econ. & $3.946,6$ & $3.626,6$ & $4.610,0$ & $4.133,2$ & $2.412,2$ & $2.171,0$ & $2.528,2$ & $3.169,4$ & $4.940,0$ & $1.999,1$ & $3.022,1$ & 378,0 \\
\hline Año firma posterior al de ef. econ. & $677.485,0$ & $488.160,0$ & 852,9 & 576,7 & $1.047,0$ & $1.217,4$ & $1.472,6$ & $2.700,2$ & 522,9 & 868,9 & 302,8 & 0,0 \\
\hline Porcentaje & & & - & - & - & - & - & - & - & - & - & - \\
\hline$\underline{\text { Convenios }}$ & - & - & - & - & - & - & - & - & - & - & - & - \\
\hline Total & 100,0 & 100,0 & 100,0 & 100,0 & 100,0 & 100,0 & 100,0 & 100,0 & 100,0 & 100,0 & 100,0 & 100,0 \\
\hline Año firma igual al de ef. econ. & 38,1 & 34,9 & 34,2 & 35,8 & 26,4 & 27,0 & 25,8 & 30,6 & 43,8 & 28,4 & 25,8 & 14,8 \\
\hline Año firma posterior al de ef. econ. & 6,6 & 7,0 & 6,6 & 7,3 & 9,0 & 8,1 & 11,6 & 16,9 & 9,2 & 6,2 & 3,3 & 0,0 \\
\hline Trabajadores & - & - & - & - & - & - & - & - & - & - & - & - \\
\hline Total & 100,0 & 100,0 & 100,0 & 100,0 & 100,0 & 100,0 & 100,0 & 100,0 & 100,0 & 100,0 & 100,0 & 100,0 \\
\hline Año firma anterior al de ef. econ. & 57,0 & 63,0 & 52,9 & 60,6 & 70,1 & 68,6 & 62,5 & 41,9 & 46,8 & 72,2 & 57,5 & 92,1 \\
\hline Año firma igual al de ef. econ. & 36,7 & 32,6 & 39,7 & 34,5 & 20,9 & 20,1 & 23,7 & 31,4 & 48,1 & 19,4 & 38,7 & 7,9 \\
\hline Año firma posterior al de ef. econ. & 6,3 & 4,4 & 7,3 & 4,8 & 9,1 & 11,3 & 13,8 & 26,7 & 5,1 & 8,4 & 3,9 & 0,0 \\
\hline
\end{tabular}

Fuente: MEYSS, Estadística de Convenios Colectivos de Trabajo.

Nota: (1) Datos provisionales. Convenios registrados hasta el 31 de mayo de 2016.

(C) Revista de Economía Laboral 
Por otra parte, en cualquier caso, sí que parece que existen razones para explicar que la crisis económica afectara al valor de la tasa de cobertura, disminuyéndola, como ocurrió realmente desde 2009 a 2012, a pesar de que, al calcular el porcentaje de los trabajadores realmente cubiertos respecto de los potencialmente cubiertos, la reducción del empleo afecte tanto al numerador como al denominador de esa tasa. Y ello porque parece que el descenso del numerador pudo ser más intenso que el del denominador a partir de 2010, por una serie de factores como el retraso en la firma de los nuevos convenios que la propia crisis pudo provocar o el abandono de algunas empresas de la negociación colectiva que pudo producirse por las dificultades de las empresas derivadas de esa crisis. Pero a partir de 2013 ese efecto se corrige y la tasa de cobertura deja de caer, hasta recuperar los valores de 2009, pese a que en 2014 ese aumento se modera y hasta vuelva a descender ligeramente, como consecuencia de que el final de la ultraactividad solo afecta ya a los convenios en los que durante el curso del año hayan transcurrido doce meses desde el momento de la denuncia del convenio, sin que se produzca la circunstancia de acumulación de 2013, que se produjo por el citado retraso transitorio de un año de ese final que se había establecido en la ley 3/2012.

Por ello, no parece que puede dictaminarse que la reforma laboral afecte negativamente a la tasa de cobertura, sino que, incluso, aumenta, aunque ello no sea necesariamente contradictorio con el posible debilitamiento de la negociación colectiva no solo como consecuencia de la crisis sino también como consecuencia de la reforma laboral, porque, como se señala en Cruz Villalón (2016), la firma de nuevos convenios en muchas ocasiones corresponden por su importancia en el tejido productivo español de las empresas a las de tamaño muy reducido, con un importante grado de dependencia de los trabajadores respecto de los empresarios y en las que la capacidad negociadora de los trabajadores es muy limitada por no decir muy escasa.

Aparte de que, independientemente del tamaño de la empresa, la firma de esos nuevos convenios se realiza en una situación en la que el final de la ultraactividad perjudica la posición en la que negocian los trabajadores o sus representantes, más aun, si se tienen en cuenta las consecuencias negativas todavía persistentes de la crisis económica en el debilitamiento de esa posición, algo que se confirma con que en casi todos los casos son los representantes de las empresas y no los de los trabajadores los que denuncian los convenios. Además, el debilitamiento de la negociación por parte de los trabajadores depende, también, como se ha señalado, de otros factores distintos a la crisis,

\footnotetext{
(C) Revista de Economía Laboral
} 
como la amenaza del despido, la posibilidad de que cuando no exista convenio el empresario modifique unilateralmente las condiciones de trabajo y el resto de los cambios que introduce la reforma laboral de 2012 en materia de negociación colectiva, como la prioridad aplicativa de los convenios de empresas y las mayores posibilidades de inaplicación o descuelgues de los convenios vigentes.

\section{La estructura de la negociación colectiva después de la crisis y de las reformas laborales}

El número de convenios con efectos económicos (convenios vigentes) con los datos de 2014 (último año para el que se disponen de datos definitivos) asciende a 5.185, casi seiscientos convenios más que en 2013 y más de ochocientos convenios por encima de 2012, rompiéndose así la señalada tendencia decreciente del número de convenios vigentes desde el inicio de la crisis hasta ese año. De ese crecimiento, casi su totalidad corresponde a los convenios de empresa, ya que se mantiene prácticamente constante el número de convenios de ámbito superior al de la empresa en los dos últimos años para los que se disponen de datos definitivos (cuadro 1). Si se utiliza el porcentaje que representan los convenios de empresa sobre el total, este porcentaje crece desde el $74,6 \%$ en 2011 al,77,2\% en 2014, lo que podría ser significativo de la incidencia de la prioridad aplicativa de los convenios de empresa aprobada sin ningún tipo de limitación por la reforma laboral de 2012 para materias tan relevantes como la jornada laboral y los salarios.

Ahora bien, estos datos deben de matizarse porque este efecto creciente se desdibuja notablemente si, en vez del número de convenios, se considerara el de los trabajadores cubiertos por esos convenios, que, aunque crecen muy ligeramente en 2013 vuelven a retroceder en 2014, lo que provoca que el porcentaje de trabajadores con convenio de empresa sobre el total de trabajadores con convenio disminuya desde el $8,7 \%$ en 2011 al $8,4 \%$ en 2014 , en todo caso un porcentaje muy reducido en relación con el correspondiente al número de convenios. Y ello porque el número de trabajadores por convenio de empresa es bastante reducido (entre 200 y 300) y, en todo caso, muy inferior al de los trabajadores con convenios de ámbito superior (en torno a 8.000) y que, además, mientras que el número de trabajadores por convenio disminuye en los convenios de empresa por la tendencia a firmar este tipo de convenio empresas cada vez de tamaño más reducido. en los 
últimos años aumenta tanto en 2013 como en 2014 en los convenios de ámbito superior al de la empresa (cuadro 1).

Por lo tanto, aunque parece que la prioridad aplicativa de los convenios de empresa está favoreciendo la firma de estos convenios, es difícil de sostener que ese cambio normativo haya provocado ya una modificación notable en la estructura de la negociación colectiva, sobre todo en lo que respecta a la importancia de los trabajadores cubiertos por los convenios, aunque sí existen indicios (que se comprueban sobre todo en 2013) de una tendencia a que los nuevos convenios se correspondan básicamente con los de ámbito de empresa. Ahora bien, esto no significa que haya que despreciar o minusvalorar la incidencia de la prioridad aplicativa de los convenios de empresa, porque los nuevos convenios de empresa que se firman cada año, como ya se ha señalado, corresponden a empresas cada vez con menor número de trabajadores, lo que implica que el tamaño medio de las empresas con convenio propio, que coincide con el número de trabajadores por convenio de empresa, baja notablemente desde 2012, de casi trescientos, hasta situarse en 2014 en algo más de doscientos (menos, incluso, de esa cifra con los datos todavía provisionales de 2015), lo que, además, significa un número de trabajadores por convenio muy inferior al de los convenios de ámbito superior: de alrededor de 200 en el primer caso a aproximadamente 8.000 en el segundo.

Porque la mayor posibilidad de suscribir convenios en las empresas de menor tamaño y la tendencia a disminuir el tamaño medio de los convenios de empresa, que son los que tienen una mayor representatividad en los convenios nuevos que se firman cada año, sí que puede suponer como señala Cruz Villalón, J (2006) un cambio de relevancia por la mayor debilidad negociadora de los trabajadores en los convenios de las pequeñas empresas que en los de las grandes empresas y, sobre todo, que en los convenios sectoriales, que agrupan a un número muy superior de trabajadores, ya que en las pequeñas y también en las medianas empresas, como ya se ha indicado, la relación de dependencia de los trabajadores con los empresarios suele ser muy elevada, aparte de que el grado de afiliación sindical y de influencia de los sindicatos es muy escaso en ese tipo de empresas.

$\mathrm{Y}$ esta mayor debilidad negociadora en los nuevos convenios de empresa firmados sí que pueden estar teniendo alguna influencia en la negociación colectiva. Máxime cuando el peso relativo de las empresas de menor tamaño, que hasta ahora engrosaba la negociación sectorial, sobre todo, provincial, y que están siendo muy afectadas por el final de la ultraactividad, es tan elevado en España, puesto que, aproximadamente, el $75 \%$ de las empresas tienen menos de seis 
trabajadores y el 85\% menos de diez, y, además el tamaño medio de las empresas pertenecientes al régimen general de la seguridad social se sitúa en torno a diez trabajadores por empresa.

Y esto puede significar, aparte de la mayor debilidad de negociación de los trabajadores de las empresas de tamaño reducido, la exclusión de la misma negociación de los trabajadores de muchas empresas por la falta de representatividad de las mismas, ya que, como prescribe el artículo 62.1 del Estatuto de los Trabajadores, solo podrán tener esa representatividad los trabajadores de las empresas o los centros de trabajo de más de diez trabajadores (alrededor del 15\% de las empresas), que puede extenderse a las empresas o los centros que tienen entre seis y diez trabajadores si así lo decidiera la mayoría de los trabajadores, aunque en este caso difícilmente sea comparable, como se ha indicado, la capacidad de negociación de esos trabajadores con las de las grandes empresas o el conjunto de un sector o rama de actividad.

Donde en cualquier caso sí se están produciendo cambios trascendentes es en la estructura de la negociación colectiva sectorial por el ámbito territorial de la misma, al pasarse de una negociación sectorial predominantemente provincial a otra en la que los convenios provinciales han perdido su hegemonía a favor no solo de los convenios de empresa en el caso de los nuevos convenios, de los firmados en el año, sino, sobre todo, de los convenios sectoriales autonómicos y de los nacionales.

Así, si tradicionalmente la situación, que todavía se mantenía en 2010, era que en torno al $20 \%$ del total de los convenios eran provinciales y que esos convenios afectaban a más de los dos terceras partes de las empresas cubiertas por los convenios colectivos (incluso en 2005 superaban las tres cuartas partes) y a más de la mitad de los trabajadores con convenio, esa distribución cambia, primero, moderadamente en 2011 y, después, radical y drásticamente a partir de 2012 y, sobre todo, en 2013.

De forma que con los últimos datos definitivos de la estadística de convenios colectivos (los correspondientes a 2014) el porcentaje de los convenios provinciales sobre el total de los convenios ya no llegaba al $14 \%$, el porcentaje de las empresas con convenio provincial no alcanzaba el 50\% de las empresas con convenio y el de los trabajadores con ese tipo de convenios era apenas la tercera parte, y, en todo caso, inferior al 40\% (35,3\% en 2013 y 36,5\% en 2014). Por el contrario, los convenios autonómicos que en 2010 significaban menos del 2\% del total de los convenios y cubrían a menos del 6\% de las empresas y a menos del 8\% de los trabajadores con convenio, en 2014 suponían prácticamente el $5 \%$ de los convenios y afectaban a alrededor del $20 \%$ 
de las empresas (más del $25 \%$ en 2013) y de los trabajadores con convenio.

Y también, aunque con menos intensidad que en el caso de los convenios autonómicos, se constata el cambio a favor de los convenios sectoriales nacionales, que, con menos del $2 \%$ del total de los convenios, tradicionalmente cubría en torno al $20 \%$ de las empresas y al $25 \%$ de los trabajadores con convenios, y que, en cambio, en 2014 con un porcentaje similar de convenios superaban el 30\% de las empresas y de los trabajadores con convenio. Por lo tanto, con los últimos datos definitivos la situación es la de un sustancial retroceso del peso relativo de los convenios provinciales en relación con la situación anterior a 2012 , tanto en lo que respecta al número de convenios como al de las empresas y los trabajadores cubiertos, en beneficio de los convenios autonómicos y nacionales, sobre todo de los primeros.

$\mathrm{Y}$ este cambio tan notable en la estructura de la negociación colectiva, ¿a qué puede deberse?, ¿qué factores lo explican?. Parece que son dos las razones de este vuelco en la importancia relativa de los convenios colectivos sectoriales, según el ámbito territorial de los mismos. La primera razón podría encontrarse en el cambio normativo que se produjo no en la reforma laboral de 2012 sino en la reforma de la negociación colectiva en el verano de 2011 y que consistió en la supresión de la posibilidad incorporada en la reforma laboral de 1994 de que los convenios provinciales modificaran los convenios de ámbito superior, autonómicos y nacionales, mientras que se mantenía esa posibilidad de modificar los convenios de ámbito superior (los nacionales) por parte de los autonómicos (posibilidad también establecida en la reforma de 1994), lo que reduce notablemente la potencialidad y entidad de los convenios sectoriales provinciales en relación con los de ámbito superior, autonómicos y nacionales. De hecho, si se comparan los datos definitivos de los convenios con efectos económicos en 2014 con los de 2011 el número de convenios provinciales disminuye de 520 a 279 , el de los convenios autonómicos crece de 38 a 102 y el de los convenios nacionales aumenta de 38 a 49 .

Y la segunda razón de carácter bastante diferente se encontraría en el final de la ultraactividad prevista por la reforma laboral de 2012, que provocó el término de la vigencia de muchos convenios y que podría haber afectado con especial intensidad a los convenios provinciales, ya que estos eran los preponderantes en cuanto a la cobertura de empresas y de trabajadores en el momento de la aprobación de la reforma y que se caracterizan por una gran fragmentación, al predominar la cobertura de empresas de reducido tamaño. Al decaer la vigencia de esos convenios provinciales muchos no se renuevan 
inmediatamente, pues la suscripción de un nuevo convenio provincial en una situación económica desfavorable para muchas empresas como era la de los años 2012 y 2013 dificultaba la nueva negociación.

Esa situación propicia en algunos casos la sustitución de un convenio provincial por otro de empresa por las mayores posibilidades de llegar a acuerdos en este último ámbito por los problemas que puede plantear llegar a acuerdos entre empresas de muy diferentes características y tamaño, aunque en otros casos las propias dificultades económicas entorpecerán la firma de los nuevos convenios, tanto de empresa como de otro ámbito, aparte de que las empresas de menor tamaño no estarán cubiertas por la negociación colectiva porque en esas empresas, según el artículo 62.1 del Estatuto de los Trabajadores, no existirá la posibilidad de representación de los trabajadores y, por consiguiente, de legitimidad para negociar un convenio de empresa.

A esta situación de empresas sin convenios puede también contribuir la falta de interés por la negociación colectiva de algunas empresas por la mayor posibilidad que tienen de modificar a la baja las condiciones de trabajo y salariales en esas empresas cuando esas condiciones no se regulen por convenio alguno, como consecuencia de uno de los cambios fundamentales de la reforma laboral de 2012, de que en esos casos las empresas puedan modificar unilateralmente las condiciones de trabajo y la cuantía salarial sin necesidad de consenso alguno con los trabajadores.

Tanto la falta de cobertura de convenios, sobre todo en las empresas de menor tamaño, como la posible sustitución de un convenio sectorial provincial por un convenio de empresa supone el debilitamiento potencial, y en muchos casos real, de los trabajadores afectados por la negociación colectiva, tanto por las dificultades económicas todavía persistentes en muchas empresas como por el menor poder de negociación a nivel de empresa de los trabajadores, en particular, en los casos de sectores muy fragmentados con gran número de pequeñas empresas, incluso muy pequeñas.

Una cuestión muy importante a tener en cuenta es que una de las razones que amparaba la reforma de la negociación colectiva en 2012, especialmente la imposición de la prioridad aplicativa de los convenios de empresa, era la creencia por parte de la gran mayoría de los economistas convencionales y de prácticamente todos los organismos económicos de que la negociación colectiva más perjudicial para los resultados económicos agregados de la economía (producción, empleo, salarios e inflación) era la de una negociación colectiva intermedia como la española en la que predominan en cuanto al número de empresas y de trabajadores cubiertos (aunque no en el 
número de convenios, en el que destacan los de empresa) los convenios sectoriales, en particular los provinciales, en detrimento de una negociación colectiva más descentralizada en la que tuvieran mayor peso relativo las empresas y los trabajadores afectados por los convenios de empresa.

Esta negociación colectiva sectorial e intermedia sería, según la economía convencional, mucho más negativa que la negociación a nivel de empresa en cuanto a las consecuencias sobre los resultados económicos porque tendría menos en cuenta en los acuerdos salariales y de las condiciones de trabajo la situación económica de cada empresa $\mathrm{y}$, en concreto, fenómenos tales como la productividad y el rendimiento de los trabajadores, así como las consecuencias y resultados de esa negociación en cada empresa, sobre todos en las más pequeñas.

Eso lleva a los economistas convencionales y organismos económicos, por otra parte claramente partidarios del mercado, en detrimento de las situaciones más colectivas, a preferir, en vez de una negociación colectiva más centralizada, una negociación colectiva en la que predominen los convenios de empresa, lo que justificará la defensa de la prioridad aplicativa de esos convenios finalmente aceptada, primero de forma limitada por el gobierno socialista en 2011 y luego de una forma imperativa por el gobierno del PP en 2012.

Pero el problema está en que, como se expone en Pérez Infante (2013b), ni los fundamentos teóricos ni la evidencia empírica justifica suficientemente la superioridad en cuanto a los resultados económicos de la negociación colectiva empresarial en relación con la sectorial. Desde el punto de vista teórico porque el análisis de la economía convencional de adaptación de las condiciones negociadas de las empresas a la situación económica de las mismas y del conjunto del país solo sería válida cuando el grado de competencia de las empresas sea muy elevado y no cuando las empresas tengan algún grado de control monopolista, lo que todavía es muy relevante en España en muchos sectores, sobre todo en algunos de los más estratégicos de la economía. En esos casos las condiciones pactadas dependerán de ese grado de control monopolista y no tienen por qué resultar beneficiosas necesariamente para los resultados agregados de la economía.

Además, también desde el punto de vista teórico, la incidencia de los salarios en el empleo según la economía convencional, como ya se señaló en la introducción, tiene en cuenta preferentemente el efecto de los salarios sobre el coste laboral de las empresas, marginando en la mayoría de las ocasiones el efecto sobre los ingresos de los trabajadores y la demanda efectiva de estos, teniendo en cuenta sobre todo las consecuencias microeconómicas del aumento salarial y apenas las 
macroeconómicas, por lo que la prioridad principal de la negociación será, según este planteamiento, aunque muchas veces no se explicite claramente, la consecución de costes laborales más reducidos, aunque ello vaya en perjuicio de los ingresos de los trabajadores y de la demanda agregada de la economía.

Y, por otra parte, la negociación muy descentralizada a nivel de empresa no solo no tiene que ser necesariamente más beneficiosa que la intermedia, como la española, sino que, incluso, puede llegar a ser más perjudicial para los resultados macroeconómicos de un país que otra negociación más centralizada que tuviera más en cuenta en la determinación de los salarios y de otras condiciones de trabajo la posible influencia en fenómenos macroeconómicos como la inflación y el empleo global que una negociación en la que predominen los intereses de cada empresa.

Y desde el punto de vista de la evidencia empírica disponible tampoco resulta tan contundente y definitiva con la información más reciente y con los estudios más actuales que la negociación colectiva de empresa sea más beneficiosa para el conjunto de la economía que otro tipo de negociación colectiva, como se expone en Pérez Infante (2008, 2011, 2013b). En efecto, tradicionalmente con base principalmente en Calmfors y Driffill (1988) se pensaba que la relación entre la estructura de la negociación colectiva, más específicamente su grado de centralización, y los resultados económicos agregados era muy clara y contundente, de forma que si la relación era con la tasa de ocupación, con el empleo, con los datos disponibles se podría obtener una curva en forma de U, en la que las mayores tasas de ocupación corresponderían a los extremos, menor grado de centralización por el dominio de la negociación a nivel de empresa, y mayor grado de centralización, en el extremo por la existencia de un solo convenio colectivo para todo el país, y las menores tasas de ocupación corresponderían a países con una negociación colectiva intermedia, de carácter sectorial, como en España, en la que, además históricamente, la negociación colectiva sectorial principal era la provincial.

Y algo parecido ocurriría, según los citados estudios realizados durante la década de los ochenta del pasado siglo, si la relación se estableciera entre el grado de negociación colectiva y otros resultados económicos, como el paro y la inflación, aunque en este caso la forma de la curva sería la de una campana o U invertida, es decir, la menor tasa de paro y la menor inflación correspondería también a países con negociación colectiva muy descentralizada o muy centralizada, correspondiéndose, en cambio, los peores resultados, la mayor tasa de 
paro y la inflación más elevada, a países de negociación intermedia, como la española.

Pero, como se ha señalado, con la información más actual, estas conclusiones no pueden mantenerse de una forma rotunda sobre todo a partir de la evidencia empírica resultante a partir de la segunda mitad de la década de los ochenta del pasado siglo, evidencia que no se recogía en el artículo de Calmfors y Driffill anteriormente citado, ya que con esa información muchos de los estudios más recientes consideran que tan importante para los resultados económicos como el grado de centralización es el grado de coordinación de la negociación colectiva y ese grado de coordinación no es siempre el mismo por cada grado de centralización, aunque, en general, estén relacionadas ambas características, soliendo ocurrir que una negociación colectiva muy descentralizada, predominantemente a nivel de empresa, sea muy dispersa, difícil de articular y muy poco coordinada y entonces los resultados económicos pueden no ser tan favorables como se concluía en estudios anteriores, por lo que es difícil mantener la existencia, según el caso, de curvas en forma de $\mathrm{U}$ o de campana invertida.

Eso es lo que se desprende de los estudios realizados por la OCDE a partir de 1997, una organización que, incluso, y paradójicamente, ha venido defendiendo y recomendando la descentralización de la negociación colectiva, aunque de esos estudios se concluyan resultados muy diferentes y contradictorios con esa defensa y recomendación (en varios de los estudios publicados en el informe anual del organismo denominado Perspectivas del Empleo, con base en datos obtenidos a partir de la segunda mitad de la década de los ochenta del pasado siglo, como los Perspectivas correspondientes a 1997, 2004 y 2006) ${ }^{28}$. Así, en estos estudios se concluye que la influencia de la estructura de la negociación colectiva o, lo que es lo mismo, de su grado de centralización, en el empleo y el paro sería poco contundente y escasamente categórica, ya que sistemas de negociación colectiva muy dispares pueden ser capaces de provocar resultados parecidos y, por el contrario, países con un grado de centralización semejante se caracterizan por resultados económicos muy distintos. Aun así, en OCDE (1997) se precisa que la tasa de ocupación (porcentaje de la población ocupada respecto de la población potencialmente activa, de 15 a 64 años) ha disminuido en los países que tendieron a reducir el grado de centralización o la coordinación de los convenios colectivos, mientras que los países que no han introducido

28 OCDE (1997), páginas 166-214, OCDE (2004), págs. 232-234 y 305-3007, y OCDE (2006), págs. 121-131. 
esos cambios y se mantuvieron con un elevado grado de centralización, pero también de coordinación, presentan una tendencia a mantener tasas de paro más bajas y tasas de ocupación más altas que esos otros países.

También en OCDE (1997)29 se expone que "los resultados estadísticos precedentes deben considerarse "negativos", en el sentido de que parece que hay pruebas poco contundentes de que exista una relación en forma de U entre la estructura de la negociación colectiva y el empleo o una relación en forma de campana entre la estructura de la negociación colectiva y la tasa de paro". O en OCDE (2004) ${ }^{30}$ que "No se observa ninguna relación sistemática entre los indicadores de la negociación de los salarios... y la tasa de crecimiento de los salarios reales agregados o de los resultados no salariales, incluida la tasa de paro" o "que unos mecanismos institucionales bastante distintos son capaces de obtener unos resultados macroeconómicos bastantes similares".

Y, asimismo, en OCDE (2006) ${ }^{31}$ se mantiene. "El hecho de que los estudios no obtengan todos ellos los mismos resultados probablemente se deba, al menos en una parte, a las dificultades para medir las estructuras y las prácticas de la negociación, así como el hecho de que un mismo mecanismo institucional puede dar resultados distintos en cada contexto económico y político", pero que "En conjunto, las investigaciones empíricas recientes,... sugieren que los sistemas de negociación caracterizados por un elevado grado de corporativismo (centralización y coordinación) tienden a lograr un paro más bajo que otros mecanismos institucionales". Y esta última afirmación es coherente con la evidencia empírica disponible, tanto de la más reciente como de la anterior, que, en ningún caso, permite asegurar que la negociación colectiva a nivel de empresa sea más beneficiosa que la que tenga un elevado grado de centralización y de coordinación (lo que es consistente hasta con las citadas curvas en forma de $\mathrm{U}$ o de campana, según el caso).

Todo lo cual nos lleva a discutir y cuestionar el planteamiento de los economistas convencionales y las recomendaciones de los organismos económicos de que una mayor descentralización de la negociación colectiva, dando más relevancia y poder a la negociación a nivel de empresa, sea necesariamente más beneficiosa para el conjunto de la economía que cualquier otro sistema alternativo de negociación

\footnotetext{
29 Páginas 2012 y 2013.

30 Páginas 229-232.

31 Páginas 124-131.
} 
colectiva. Es más parece que con los estudios realizados por la OCDE la conclusión sería muy diferente y existen indicios de que la relación entre los grados de centralización y coordinación y el empleo sea directa (creciente) y entre esos grados y el paro indirecta (decreciente), y, por lo tanto, los sistemas más beneficiosos para el empleo y el paro resultarían los que se caracterizan por una negociación colectiva muy centralizada y muy coordinada. Por lo tanto, estos indicios deberían llevar más que a la defensa de mayor descentralización de la negociación colectiva y de la prioridad aplicativa de los convenios de empresa a la defensa de una negociación muy diferente, más centralizada y más coordinada, sobre todo, más coordinada, que la que ha existido tradicionalmente en España.

Aparte de que una mayor descentralización (recuérdese que en España ya las dos terceras partes de los convenios son de empresa) produciría una mayor dispersión y proliferación de los convenios colectivos, lo que afectaría desfavorablemente a la articulación y coordinación de los convenios colectivos, ya bastante limitadas y

escasas. A este respecto hay que tener en cuenta que ya en la situación actual por cada mil trabajadores con convenio se necesitan firmar cinco convenios, lo que en el caso de los convenios de empresa asciende a casi cincuenta, por lo que una mayor extensión de los convenios colectivos de empresa aumentaría el número de convenios que sería necesario firmar para mantener la cobertura actual. Y una mayor dispersión de la negociación colectiva, aparte de que iría acompañada, como parece obvio, y se ha señalado anteriormente, de una menor articulación de los convenios y una coordinación de los convenios más difícil, supondría, sin duda, una menor capacidad para influir en las condiciones de trabajo y salariales por parte de los trabajadores, sobre todo si se tiene en cuenta el tejido productivo español en el que predominan las empresas de tamaño muy reducido en cuanto a la plantilla de trabajadores.

\section{Consecuencias económicas del debilitamiento de la capacidad negociadora de los trabajadores}

El efecto más claro y constatable con los datos disponibles de la pérdida de la capacidad negociadora de los trabajadores, como para el caso de la flexibilidad laboral prevé la propia economía neoliberal y defendían los organismos económicos más influyentes, ha sido la devaluación salarial, no solo por el menor crecimiento de los salarios pactados, minoración que, incluso, hasta 2014, ha superado al retroceso 
de la inflación, pasando el aumento de los salarios de superar el 4\% en 2007 a situarse por debajo del 1\% en los tres últimos años, 2013, 2014 y 2015 (el 0,5\% en los dos primeros años y el 0,8\% en el tercero), sino por otras razones adicionales que han hecho que el incremento de los salarios brutos efectivamente percibidos por los trabajadores haya sido todavía menor al pactado, hasta llegar a tomar las variaciones de esos salarios valores negativos desde 2012 hasta 2014 .

Entre estas razones que provocan una deriva salarial negativa, que el crecimiento de los salarios brutos percibidos por los trabajadores sea inferior al de los salarios pactados en los convenios colectivos, figuran algunas muy relacionadas con la crisis económica y las últimas reformas laborales, tales como la reducción o hasta desaparición de algunos complementos vinculados a las ventas o los beneficios de las empresas, la disminución de las horas trabajadas y, en particular, de las horas extraordinarias, que en muchas empresas se suprimen, aparte del número creciente, como se deduce de la Encuesta de Población Activa (EPA), de las horas extraordinarias no pagadas, la posibilidad creciente de inaplicación en materia salarial de convenios colectivos y la posibilidad de disminución de los salarios por decisión unilateral de los empresarios sin ningún tipo de consenso o acuerdo con los trabajadores.

Y esa devaluación salarial ${ }^{32}$, que ha supuesto una pérdida del poder adquisitivo medio de los trabajadores de más de siete puntos porcentuales desde 2010 hasta 2014 y que ha significado hasta una evolución negativa de los mismos salarios nominativos o nominales desde 2012 a 2014, ha sido, sobre todo, una devaluación de los salarios más bajos, ya que se ha concentrado principalmente en ese estrato salarial. En efecto, como se muestra en Pérez Infante (2015d), mientras que, según la Estadística de Deciles Salariales de la EPA del INE, cuyos últimos datos se refieren a 2014, el salario medio del 10\% de los trabajadores que más ganan crece desde 2008, con un incremento global en el período considerado de más del 25\% (el 25,8\%), el salario medio del $10 \%$ de los trabajadores que menos ganan disminuye continuamente desde 2008 hasta 2014, llegando a retroceder en el conjunto del período el 18\%. Esta divergente evolución salarial entraña que la ratio entre el salario medio del 10\% que más ganan y el $10 \%$ que menos ganan crezca desde 7,3 en 2007 hasta 9 en 2010, 10,6 en 2012 y 11,2 en 2014: es decir, el salario medio de los trabajadores que más ganan en ese último año supera en más de once veces al de los

32 Para el análisis del fenómeno de la devaluación salarial puede verse Pérez Infante (2013a, 2015b, 2015c, 2016a, 2016b). 
trabajadores que menos ganan, cuando en 2007 esa relación era superior a algo más de siete veces ${ }^{33}$.

Además, aunque menos intensa y generalizadamente que el grupo de trabajadores asalariados del 10\% que menos ganan, la devaluación salarial también se produce en otros colectivos de trabajadores con salarios inferiores a la media. En concreto, el salario medio de los trabajadores que se encuentran entre el $10 \%$ y el $20 \%$ que menos ganan retrocede desde 2009, el salario medio de los que se hayan entre el $20 \%$ y el $30 \%$ que menos ganan cae desde 2010 y el salario medio de los que se encuentran entre el $30 \%$ y el $40 \%$ que menos ganan se reduce desde 2011. Por el contrario, el salario medio del $60 \%$ que más ganan aumenta ininterrumpidamente desde el inicio de la crisis económica.

Y, también, con la Estadística de Deciles Salariales de la EPA, se observa que desde el inicio de la crisis el descenso hasta del salario monetario se produce, principalmente, entre los trabajadores que menos tiempo llevan ocupados en las empresas, es decir, los de nueva entrada en las empresas, y que, en concreto, llevan menos de un año contratados, mientras que el salario medio de los trabajadores de mayor antigüedad, que más tiempo llevan trabajando en las empresas, ha continuado aumentando, pese a la crisis económica, la política de austeridad y las reformas laborales aprobadas. De hecho, la ratio entre el salario medio de los trabajadores que llevan, al menos, diez años ocupados en las empresas, y el salario medio de los que llevan menos de un año en las empresas, que era 1,3 en 2007 crece hasta el doble en 2014.

$\mathrm{Y}$, al contrario de lo que mantienen sus defensores y una parte importante de los economistas convencionales, la devaluación salarial, concentrada, sobre todo, en los menores salarios, junto con la estrategia de austeridad fiscal, no ha servido para estimular el crecimiento económico ni mejorar la competitividad exterior de las empresas españolas. Y no ha servido para estimular el crecimiento económico por el efecto contractivo sobre la demanda agregada de la austeridad fiscal y la pérdida de poder adquisitivo de los trabajadores, que ha podido contrarrestar el efecto positivo que sobre el empleo haya podido tener la reducción de los costes laborales, y que parece que ha tenido como resultado más notorio el agravamiento de la crisis en 2012 y primera mitad de 2013: por muy barato que sea contratar el aumento de la producción y del empleo no se plasmará en la realidad si no va acompañado de un crecimiento de la demanda que lo ampare. Y es que

${ }^{33}$ Véase Pérez Infante (2015d, 2016b). 
la recuperación de la actividad económica que se produce a partir del verano de 2013 se debe a otras razones muy diferentes a las de la estrategia de austeridad y de devaluación salarial, exógenas tanto a la economía española como a las decisiones de las autoridades económicas nacionales, como la flexibilización temporal autorizada por la UE para el cumplimiento del objetivo de déficit del 3\% del PIB, la política monetaria expansiva del BCE, la devaluación del euro y la caída de los precios del petróleo.

Y tampoco ha servido de forma clara la política de devaluación salarial para mejorar la competitividad de la economía española, que depende de los precios relativos nacionales respecto de los exteriores y de la evolución del tipo de cambio nominal del euro ${ }^{34}$ y que, como se ha explicado en varias ocasiones ${ }^{35}$, no se ha producido en la mayoría de los años en relación con los países más desarrollados ${ }^{36}$, más concretamente con los de la zona del euro, la UE y la OCDE, y cuando se ha producido esa mejora ha podido deberse a otros factores diferentes a la devaluación salarial, como la depreciación nominal del euro.

El problema, además, tanto de la austeridad como de la devaluación salarial es que puede condicionar considerablemente el futuro de la sociedad española $\mathrm{y}$, desde luego, las posibilidades venideras de crecimiento de la economía española, pues las consecuencias más nítidas de ambas estrategias han sido, como consecuencia, entre otros factores, del avance del paro, de la importancia creciente del paro de larga duración, que, además va acompañada de la disminución de la tasa de cobertura de las prestaciones por desempleo, de la precarización del empleo cada vez mayor y la devaluación salarial que acabamos de señalar, el aumento de la pobreza y de la desigualdad, más que favorecer el crecimiento económico y la creación de empleo de la economía española.

\footnotetext{
${ }^{34}$ La competitividad de una economía se mide por el tipo de cambio efectivo real que se obtiene multiplicando la relación de precios nacionales y extranjeros (PN/PE) por el tipo de cambio nominal (tcn): tcer $=\mathrm{PN} / \mathrm{PE} \times \mathrm{tcn}$. Una mejora de la competitividad se produce cuando disminuye el tipo de cambio efectivo real y un empeoramiento cuando aumenta esa magnitud.

35 Pérez Infante (2013a, 2013c, 2015b, 2016a, 2016b).

36 Utilizando los índices de precios de producción para el conjunto de la zona del euro, el conjunto de la UE y el conjunto de los países desarrollados, calculados con los datos proporcionados por el Banco de España.
} 


\section{Conclusiones y reflexiones finales}

El artículo pretende analizar la incidencia de la crisis económica y la estrategia seguida por el Gobierno, sobre todo en materia de reformas laborales, en la negociación colectiva y, especialmente, en la capacidad negociadora de los trabajadores, si esta se debilita o no por esas razones.

De hecho, tanto la crisis económica con sus efectos sobre la destrucción del empleo y el aumento del paro como las reformas laborales aprobadas en los últimos años, sobre todo las introducidas desde febrero de 2012, así como la evolución del empleo desde la recuperación económica iniciada a mediados de 2013, parecen ir en la dirección de favorecer un mayor debilitamiento de la capacidad negociadora de los trabajadores, tanto por la presión creciente que supone el aumento del paro y la precariedad del empleo, como por la política de austeridad y las reformas laborales flexibilizadoras y desregularizadoras de las relaciones y de las condiciones de trabajo de los últimos años.

Pero ese mayor debilitamiento de la capacidad negociadora de los trabajadores no parece que vaya unido a una reducción de la tasa de cobertura de la negociación colectiva, cuando esta se calcula en porcentaje, en relación con los trabajadores potencialmente afectados por la negociación colectiva, debido a que las reformas laborales han podido tener efectos contradictorios sobre los trabajadores cubiertos por los convenios, uno negativo por el propio debilitamiento de la negociación colectiva y otro positivo por el fin de la ultraactividad y la necesidad de firmar nuevos convenios al dejar los anteriores de estar vigentes.

Y, por otro lado, la prioridad aplicativa de los convenios de empresa parece que sí está favoreciendo la firma de nuevos convenios de empresa, aunque ello no se refleje en un avance sustancial del porcentaje de los trabajadores con este tipo de convenios por varias razones, como la elevada importancia todavía mantienen de los convenios plurianuales firmados en años anteriores y el reducido tamaño de las empresas con convenio propio muy inferior al de las empresas con convenio de ámbito superior, aparte de que las empresas que firman nuevos convenios cada vez sean de menor tamaño.

Pero como se explica en el artículo lo verdaderamente importante para la capacidad negociadora de los trabajadores no es ni la evolución de la tasa de cobertura de los convenios ni los cambios en 
la estructura de la negociación colectiva entre convenios de empresa y de ámbito superior, sino que depende, por un lado, de en qué condiciones quedan los trabajadores sin convenio colectivo o en las que tienen que firmar el nuevo convenio colectivo, en ambos casos por el final de la ultraactividad y, por otro lado, en la misma posibilidad de que una empresa de reducido tamaño pueda negociar un convenio propio que pueda modificar a la baja las condiciones de trabajo previstas en un convenio de ámbito superior. Máxime, esto último, cuando el $85 \%$ de las empresas españolas tienen menos de diez trabajadores y la fuerza y capacidad de negociación de los trabajadores es muy escasa y reducida.

Aparte de que, como se explica en el artículo, los cambios que se han introducido en las relaciones laborales de los últimos años han tenido un carácter muy desequilibrador y desigual, favoreciendo el poder de los empresarios en detrimento del de los trabajadores, no solo por las modificaciones específicas de la negociación colectivo, sino por otras modificaciones normativas, como el abaratamiento y mayor facilidad del despido y la posibilidad de modificar las condiciones de trabajo unilateralmente por el empresario sin necesidad de consenso o acuerdo alguno con los trabajadores.

Y esa pérdida o debilitamiento de la capacidad negociadora de los trabajadores ha tenido como consecuencia más notable y patente la devaluación salarial, que se refleja en una pérdida muy notable del poder adquisitivo de los trabajadores desde finales de 2009 e, incluso, en la disminución de los salarios monetarios desde 2012 a 2014. Y el efecto de esta devaluación salarial no parece que haya afectado favorablemente al empleo, porque el descenso de este se acentuó en 2012 y primer semestre de 2013 y porque el aumento del empleo que acompaña a la recuperación económica que se inicia en el tercer trimestre de 2013, que, además es cada vez más precario, no se puede explicar por la propia devaluación salarial sino por factores totalmente ajenos a la economía española y a las decisiones de las autoridades nacionales.

Y, en cambio, la devaluación salarial, junto con el aumento del paro y la precarización del empleo, si que parece que ha tenido otros efectos muy diferentes, en concreto, el aumento de la desigualdad y la pobreza.

Solo un cambio radical del modelo de sociedad que no tenga como objetivo principal debilitar la posición de los trabajadores en el conjunto de las relaciones laborales ni como consecuencia más relevante el aumento de la pobreza y de la desigualdad puede alterar la situación actual y puede provocar una mejora del bienestar y del nivel 
de vida de los trabajadores y de la mayoría de la sociedad, lo que no será posible sin un reparto de la carga de la crisis económica y de los costes de la salida de esa crisis más equitativa y equilibrada que la que realmente se ha producido hasta ahora.

Pero ello no será viable ni factible sin un cambio drástico en la regulación laboral, centrada hasta ahora en la flexibilidad y la desregulación, de forma que el marco de las relaciones laborales sea menos desequilibrado que el dominante hasta ahora y que se ha ido acentuando con las últimas reformas laborales; sin una reforma fiscal en profundidad y de envergadura que aumente la presión fiscal de los más ricos evitando las desigualdades actuales y superando la situación actual de una carga fiscal mucho mayor a las rentas de trabajo que a las de capital; y sin un proceso de recuperación, consolidación y extensión del estado de bienestar que tanto ha sufrido con las políticas de austeridad seguidas desde la primavera de 2010.

$\mathrm{Y}$ todos esos cambios en materia laboral, fiscal y de bienestar social no podrán conseguirse sino se produce una modificación sustancial en el papel del sector público y una ruptura con el planteamiento neoliberal de la economía y la sociedad. Y a esa necesaria ruptura con el neoliberalismo que ha caracterizado en los últimos años a la política económica y la estrategia social de las autoridades tanto españolas como de la Unión Europea, debiera añadirse un cambio sostenido y persistente del modelo de producción, de crecimiento y de sociedad, que reoriente las actividades económicas a favor de un mayor equilibrio productivo, que no se centre tanto en actividades de carácter estacional, temporal y muy inestables, y fluctuantes y que mejore considerablemente el sistema educativo, favorezca una mayor utilización de tecnologías innovadoras y de mano de obra cualificada y una sustancial mejora de la calidad del empleo y del trabajo.

\section{Bibliografía}

Blanchard, O., Amighini, A. y Giavazzi, F. (2012): Macroeconomía, Pearson, Madrid.

Calmfors, L. y Driffill, J. (1998): "Bargaining, structure, corporation and macroeconomic performance", Economic Policy, 6. 
Casas, M.E. (2014): "La eficacia y la eficiencia del Derecho del Trabajo: reflexiones sobre un Derecho cuestionado por la economía y el desempleo", Relaciones Laborales, 10, año 30, tomo I.

Casas, M.E., Rodríguez-Piñero, M. y Valdés Dal-Ré, F (2013): "La aplicación de la reforma laboral”, Relaciones Laborales, 12.

Cebrián, I. (2016): "La reforma laboral de 2012 y la flexiseguridad. Aspectos económicos”, en J.I. Pérez Infante y S.M. Ruesga (coords.).

Cruz Villalón, J. (2016): "La nueva regulación de la negociación colectiva en España: Ruptura del equilibrio en las relaciones laborales en aras de una flexibilidad sin consenso", en J.I. Pérez Infante y S.M. Ruesga (coords.).

García, N.E. (2014): "Las causas de la doble recesión de España 20082013”, en N.E. García y S.M. Ruesga (coords.).

García, N.E. y Ruesga, S.M. (coords.) (2014): ¿Qué ha pasado con la economía española. La Gran Recesión 2.0 (2008 a 2013), Ed. Pirámides, Madrid.

Gómez, V. (2009): La reforma laboral en España, Editorial Biblioteca Nueva, Fundación Ortega y Gasset, Madrid.

Gómez, V. (2016): “El legado de la reforma de 2012”, en J.I. Pérez Infante y S.M. Ruesga (coords.).

Guamán, A. e Illueca, H. (2012): El huracán neoliberal. Una reforma laboral contra el trabajo, Sequitur, Madrid.

OCDE (1997): "Los resultados económicos y la estructura de la negociación colectiva", en Perspectivas del empleo, 1997. Traducción del Ministerio de Trabajo y Seguridad Social, Madrid.

OCDE (2004): "La fijación de los salarios: aspectos institucionales y resultados", en Perspectivas del empleo, 2004. Traducción del Ministerio de Trabajo e Inmigración, Madrid.

OCDE (2006): "Medidas generales para mejorar las oportunidades de empleo para todos", en Perspectivas de empleo, 2006. Traducción del Ministerio de Trabajo e Inmigración, Madrid. 
Pérez Infante, J. I. (1999): "Las reformas laborales recientes: objetivos, contenidos y efectos", Cuadernos de Información Económica, 150, septiembre.

Pérez Infante, J. I. (2008): "Negociación colectiva y salarios: aspectos meteorológicos, evolución y situación actual", Arxius, 18 (número monográfico dedicado a "Relaciones Laborales en España: problemas y retos").

Pérez Infante, J.I. (2009): “Objetivos y contenidos de las reformas laborales y propuestas de futuro", Circunstancias, 20, Fundación Ortega y Gasset. Publicado en V. Gómez (ed.).

Pérez Infante, J. I. (2010a): "El mercado laboral y la reforma laboral", Boletín de Inflación y Análisis Macroeconómico Flores de Lemus, Universidad Carlos III de Madrid, segunda época, 190, julio.

Pérez Infante, J. I. (2010b): "La reforma laboral después de la Ley 35/2010”, Boletín de Inflación y Análisis Macroeconómico Flores de Lemus, Universidad Carlos III de Madrid, segunda época, 194, noviembre.

Pérez Infante, J. I. (2011): "La negociación colectiva y los salarios en España. Un análisis agregado”, Cuadernos de Relaciones Laborales, 29(2).

Pérez Infante, J.I. (2013a): "Crisis, reformas laborales y devaluación salarial”, Relaciones Laborales. Revista Crítica de Teoría y Práctica, 10, año 29 , octubre.

Pérez Infante, J.I. (2013b): "Las reformas de la negociación colectiva desde una perspectiva económica”, Temas Laborales. Revista Andaluza de Trabajo y Bienestar Social, 120/2013.

Pérez Infante, J.I. (2013c): "Crisis económica, empleo y salarios". Documentación Social”, Revista de Estudios Sociales y de Sociología Aplicada, 169.

Pérez Infante, J. I. (2014): "La negociación colectiva en 2013: problemática, estadística, características y estructura", en Objetivo del Trabajo. Anuario de Relaciones Laborales UGT 2014, Marcial Pons. 
Pérez Infante, J. I. (2015a): "La negociación colectiva en 2014: evolución, estructura y salarios", en Objetivo del Trabajo. Anuario de Relaciones Laborales UGT 2015, Marcial Pons.

Pérez Infante, J. I. (2015b): "Las reformas laborales en la crisis económica: su impacto económico", Ekonomiaz, 87, primer semestre (número monográfico "Crisis salarial, paro y desigualdad. ¿Cual es el futuro del empleo?”).

Pérez Infante, J. I. (2015c): "Las reformas laborales aprobadas durante la crisis económica: una perspectiva económica", Revista de Economía Laboral, 12 (número monográfico "Las reformas laborales y la crisis económica. Consecuencias y efectos económicos").

Pérez Infante, J. I. (2015d): "Flexibilidad y reformas laborales", Documentación Social, 178/2015.

Pérez Infante, J. I. (2016a): "El impacto económico de la reforma de la negociación colectiva de 2012”, en J.I. Pérez Infante y S.M. Ruesga (coords.).

Pérez Infante, J. I. (2016b): La devaluación salarial en España: causas y consecuencias, Fundación Largo Caballero (en imprenta).

Pérez Infante, J. I. (2017): "La estadística de convenios colectivos y la medición de la cobertura de la negociación", Temas Laborales (en imprenta).

Pérez infante, J. I. y Ruesga, S. M. (coords.) (2016): "Reformas laborales en la Gran Recesión”, Tirant Lo Blanch, Valencia.

Ruesga, S. M. (2016): "Crisis económica y reformas laborales", en J.I. Pérez Infante y S.M. Ruesga (coords.).

Sraffa, P. (1960): Production of commodities by means commodities, Cambridge University Press. Existe traducción en 1965 en Oikos-Tau, Barcelona.

Valdés Dal-Ré, F. (2016): "La reforma laboral de 2012-2014: reflexiones críticas sobre la fuente prioritaria y las materias reguladas", J.I. Pérez Infante y S.M. Ruesga (coords.). 